\title{
TUNNEL ROAD SAFETY: A LOOK AT OLDER DRIVERS' PERFORMANCE AND SIGHT IMPAIRMENT
}

\author{
A Thesis \\ presented to \\ the Faculty of California Polytechnic State University, \\ San Luis Obispo
}

\begin{abstract}
In Partial Fulfillment
of the Requirements for the Degrees

Master of City \& Regional Planning

Master of Science in Engineering (Transportation Planning Specialization)
\end{abstract}

by

Edith Lopez Victoria

March 2014 
(C) 2014

Edith Lopez Victoria

ALL RIGHTS RESERVED

Page ii 
TITLE:

AUTHOR:

DATE SUBMITTED:

COMMITTEE CHAIR:

COMMITTEE MEMBER:

COMMITTEE MEMBER:
Tunnel Road Safety: A Look at Older Drivers' Performance and Sight Impairment

Edith Lopez Victoria

March 2014

Dr. Cornelius Nuworsoo, Associate Professor

City \& Regional Planning Department

Dr. Anurag Pande

Assistant Professor

Civil Engineering Department

Chris Clark, JD, Lecturer

City \& Regional Planning Department 


\begin{abstract}
Tunnel Road Safety: A Look at Older Drivers' Performance and Sight Impairment Edith Lopez Victoria
\end{abstract}

In California, there is an observed trend in which collisions cluster in and around tunnels. The break in road continuity created by the tunnels disturbs traffic flow that can lead to collisions. One of the main contrasts between open roads and tunnel roads occurs in lighting. Drivers with sight deficiencies are unable to adapt their sight to the change in the lighting environment and may crash due to misperception of road alignment, vehicle's speed and other physiological reactions, such as tension. The suspect population group of crashes occurring under the influence of tunnels conditions is older drivers. The literature suggests that sight and driving performance deteriorate with age. This research attempted to validate this claim by performing a study that looked at driver and crash characteristic of injury and fatal collisions that occurred in and around tunnels. The expectation was that a greater proportion of the older population, 60 years and older, would be represented in the crash data. However, this study found that it is young drivers and not older drivers who are more likely to crash in and around tunnels. This finding may be explained by the State of California's vision requirements for the issue of a driver's license, and the voluntary retirement of drivers that feel that they can no longer drive safely.

Page iv 
A second explanation may be that high-risk taking behavior exhibited in younger drivers overcompensates for the physical impairments exhibited in older drivers. 


\section{ACKNOWLEDGMENTS}

I would like to dedicate this thesis to my thesis committee, thank your for all your help. A special thank you goes for Professor Nuworsoo for guiding me throughout the process and for being patient and supportive every time I explored a different thesis topic. Additionally, thank you to my family and friends who supported me throughout my thesis writing process. 


\section{TABLE OF CONTENTS}

List of Tables

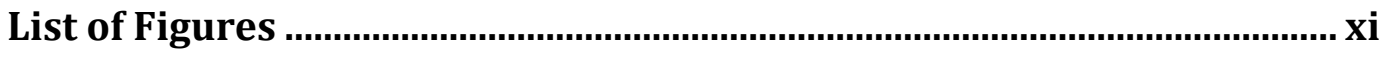

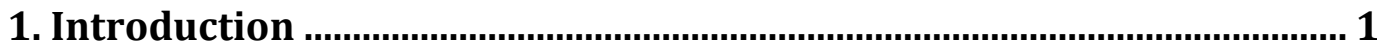

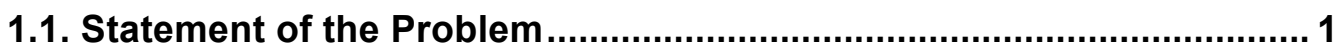

1.2. Statement of Purpose .................................................................... 3

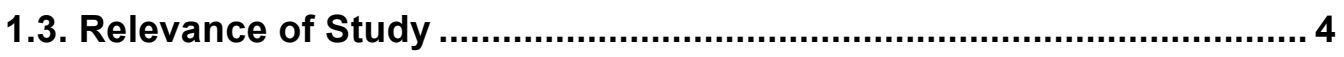

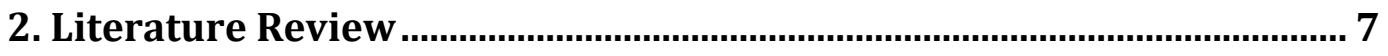

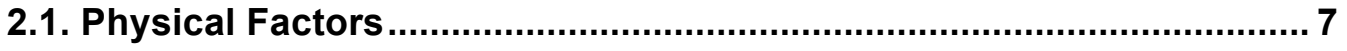

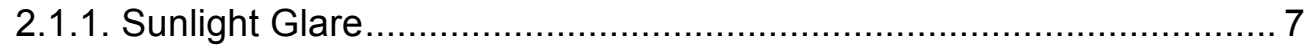

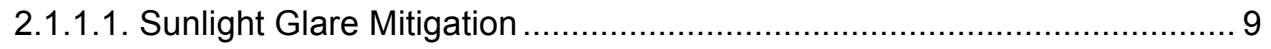

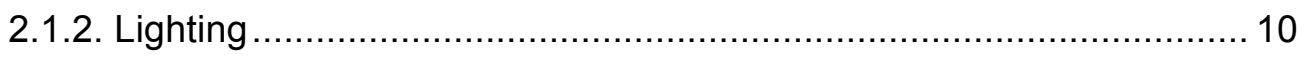

2.1.2.1. Flickering and Rhythmic Lighting ............................................ 11

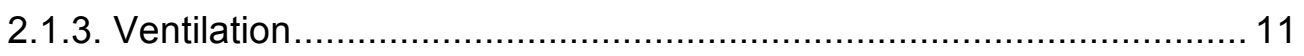

2.2. Human Factors .............................................................................. 12

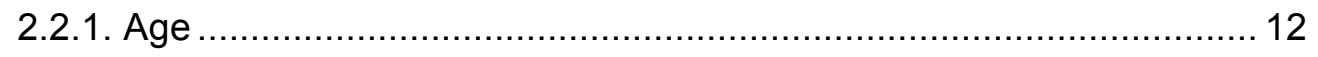

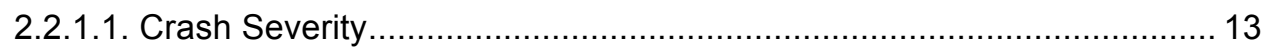

2.2.1.2. Driving Behavior and Performance .................................................... 13

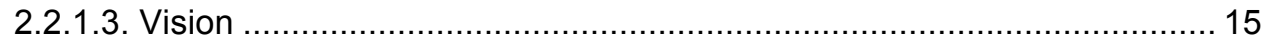

2.2.1.4. Physiological and Psychological Factors ...................................... 22

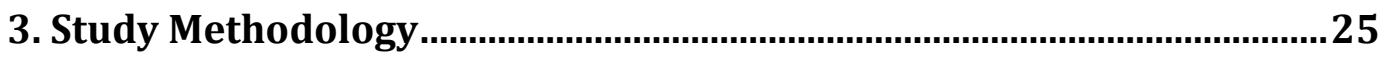

3.1. Data

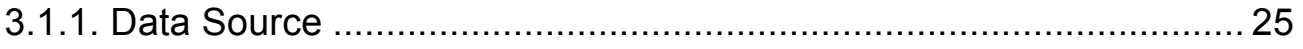

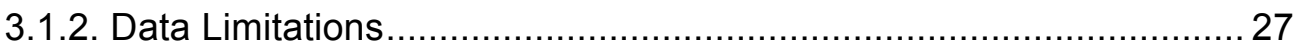

Page vii 
3.2. Analytic Framework ................................................................... 28

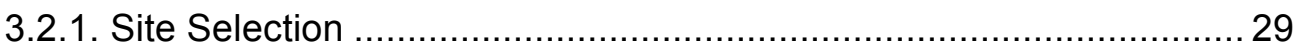

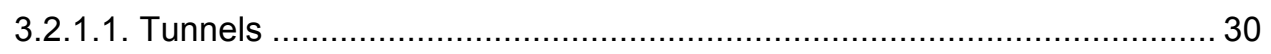

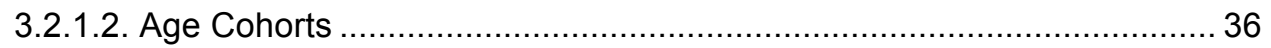

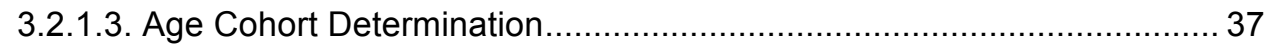

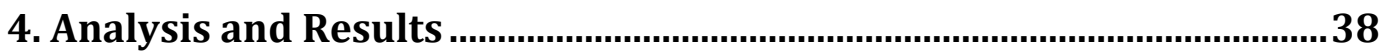

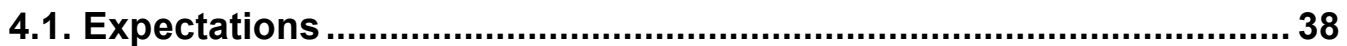

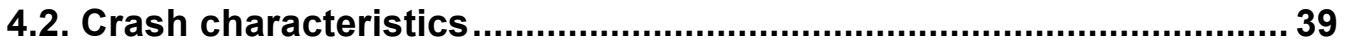

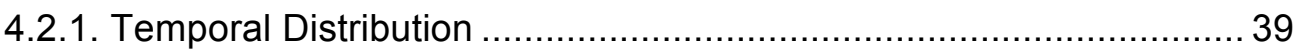

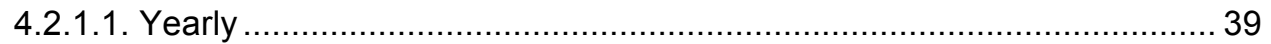

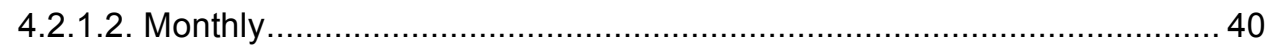

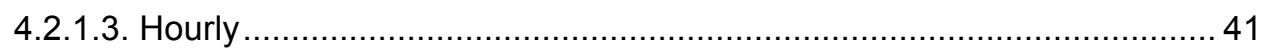

4.2.1.4. Tunnel Location - Entrance, In Tunnel and Exit .................................. 45

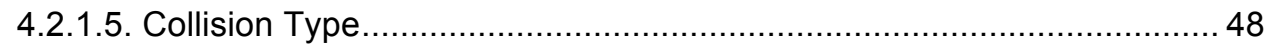

4.2.2. Driver and Party Characteristics........................................ 50

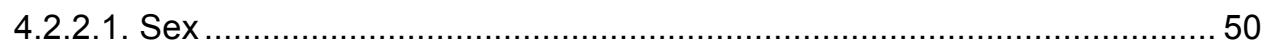

4.2.2.2. Old Drivers vs. Young Drivers .................................................... 51

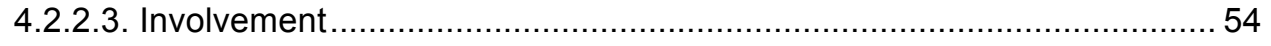

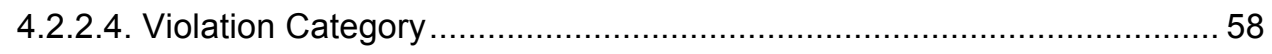

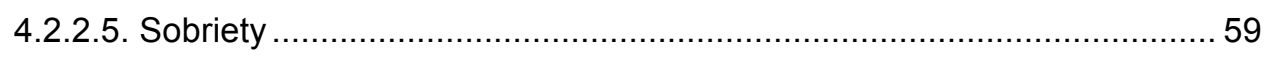

5. Conclusion and Recommendations ..................................................62

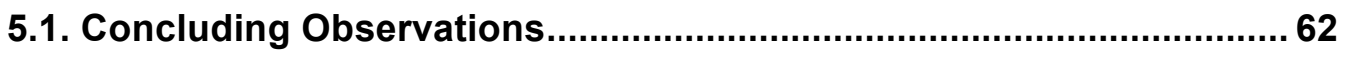

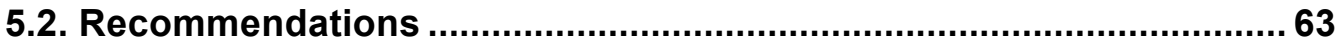

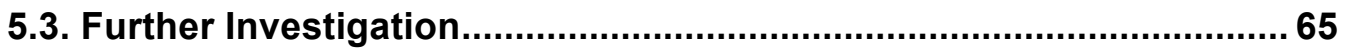

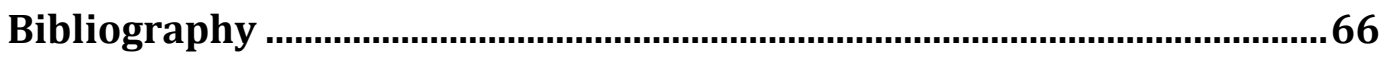




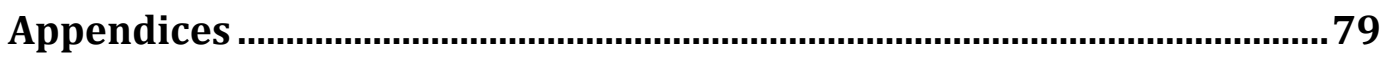

A. Population Projections................................................................ 80

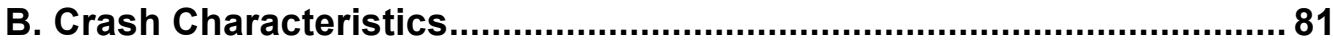

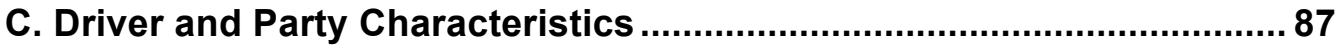

D. Population Proportion Analysis ........................................................ 92 


\section{LIST OF TABLES}

Table 1. Mean Minimum Speed (km/h) Reached During Hazard...................... 14

Table 2. Information Provided in Crash Records .........................................26

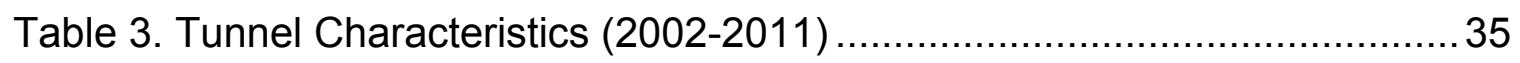

Table 4. Tunnel Location: Chi-Square Frequency (2002-2011) .......................47

Table 5. Age Distribution of Percent Involve in Crash and Age Percentage .......52

Table 6. Crash Severity - Chi-Square Frequency (2002-2011) .......................57

Table 7: Sobriety - Chi-square Frequency (2002-2011) ...............................61 


\section{LIST OF FIGURES}

Figure 1. Cluster Map of Tunnel Crashes ......................................................... 3

Figure 2. Age Distribution Projections for California $(2000-2030) \ldots \ldots \ldots \ldots \ldots \ldots \ldots . . .6$

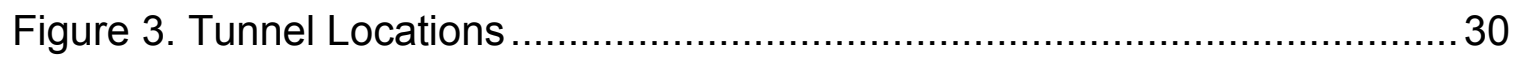

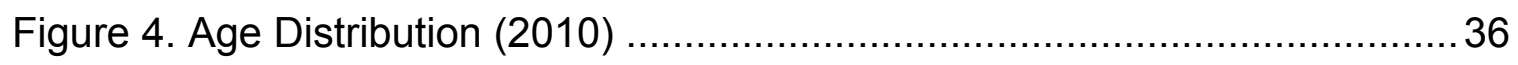

Figure 5. Yearly Distribution of Crashes (2002-2011) ….................................. 39

Figure 6. Monthly Distribution of Crashes (2002-2011) ................................. 41

Figure 7. Crash Distribution by Lighting and Age Cohort (2002-2011) ..............43

Figure 8. Hourly Crash Distribution by Age Cohort (2002-2011) …...................44

Figure 9. Crash Distribution by Tunnel Location and Age Cohort (2002-2011) .. 46

Figure 10. Crash Distribution by Crash Type and Age Cohort (2002-2011) .......49

Figure 11. Crash Distribution by Sex and Age Cohort (2002-2011) .................51

Figure 12. Lorenz Curve: Crashes vs. Population .........................................53

Figure 13. Age Distribution of Parties Involved in a Crash ................................55

Figure 14. Age Distribution of Crash Severity (2002-2011) ............................56

Figure 15. Crash Distribution by Age and Violation Category (2002-2011) .......58

Figure 16. Crash Distribution by Driver Sobriety and Age..............................60 


\section{INTRODUCTION}

\subsection{Statement of the Problem}

The spatial distribution of road collisions tends to cluster where tunnels exist, particularly at the entrances and exits. The majority of collisions that occur along tunnel roads are attributed to drivers (Wang, Liu and Zhao, 2009). Spatial clustering of crashes may indicate deficiencies in the road or driver reaction to a unique or conflictive feature in the road environment, such as tunnels, ramps and intersections. Figure 1 shows an example of the concentration of crashes at both ends of the Yerba Buena tunnel in the San Francisco Bay Area. Transportation Planning and Engineering professionals are always seeking ways to improve safety in collision prone type settings. This is done by implementing policies and/or designing roads that compensate for deficiencies in driving or driver performance. The first step in addressing a safety concern is to identify the problem, and in this case, the problem is the clustering of crashes within and on approaches to tunnels. The second step would be to identify potential contributing factors that are triggering or exacerbating the high incidence and clustering of collisions in tunnel roads.

Tunnels are perceived as disruptive in road continuity and traffic flow because they are an unusual setting for drivers, due to the abrupt environmental contrast that tunnels create along a monotonous highway or road. One of the major contrasts between open road and tunnel road conditions is lighting. Artificial lighting lights up the tunnels, and in most tunnels lighting intensity is not 
adjusted mimic open road lighting. During the day the sunlight illuminates open roads and tunnels are perceived as dark, and at nighttime, tunnels are perceived as too bright when there are no streetlights along the open road. Lighting is very important because light is an enabling and disabling function of vision. Bright or dim lighting conditions can limit vision, but the human eyes are gradually able to adapt to the change in lighting. However, adaptation to lighting contrast between open road lighting and tunnel lighting is not automatic in the vision of some drivers, and this transition may disable their sight for as much as 3 seconds (Wolfson and Graham, 2000; Tasman and Jaeger, 2004) Three seconds of driving impairment is sufficient to trigger a collision. 
Figure 1. Cluster Map of Tunnel Crashes

Tunnel Crash Distribution: Yerba Buena Tunnel (2002-2011)

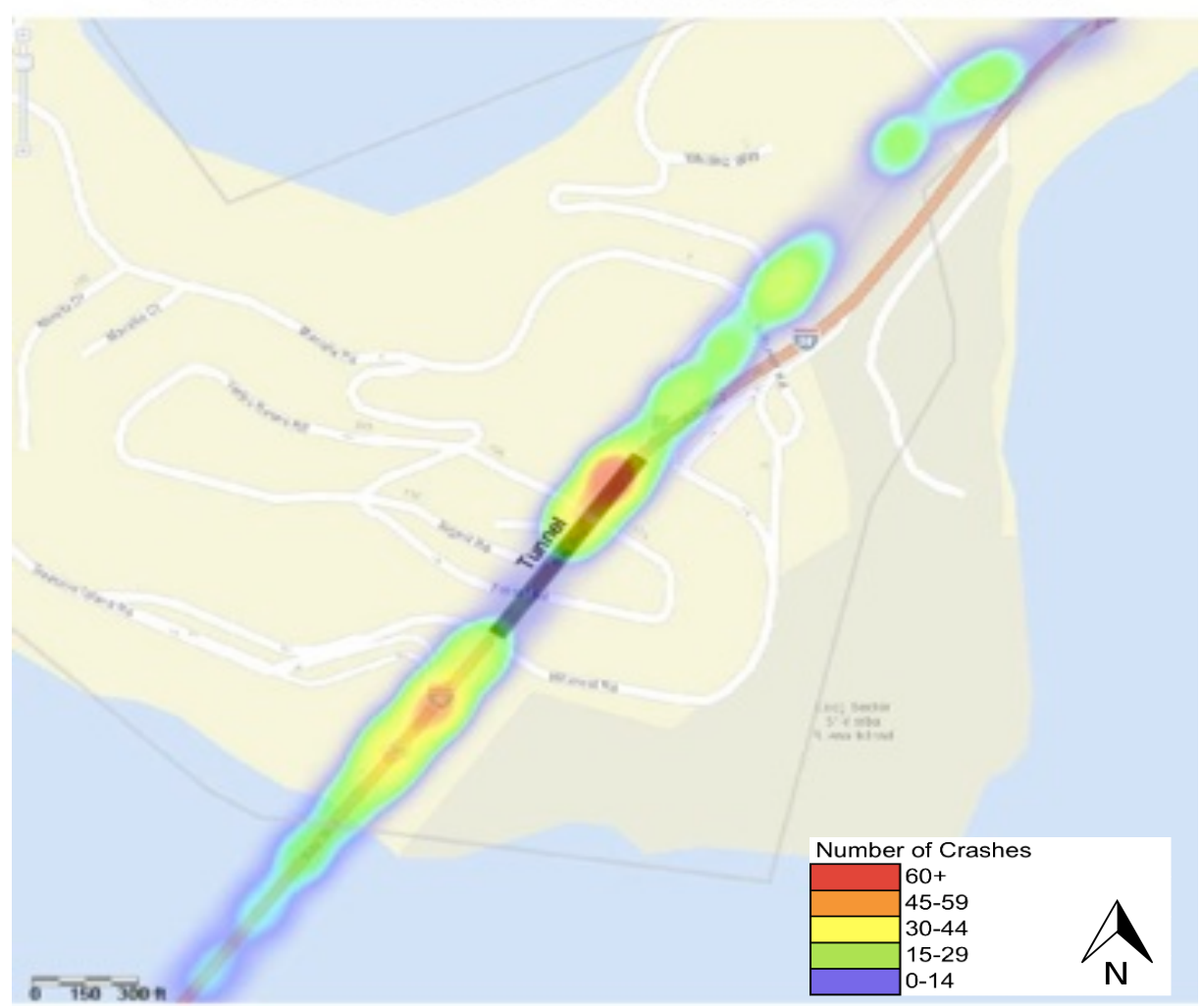

\subsection{Statement of Purpose}

This thesis attempts to identify a key-contributing factor in drivers that is correlated to the clustering of collisions at tunnel roads. Due to the nature of intunnel lighting environment, a probable cause of crashes is deficiency of vision among drivers. The population that is more likely to suffer vision impairments are older drivers, 60 years of age, or older. Numerous studies suggest that eyesight deteriorates with age and it also becomes more sensitive to automatic changes in the environment, resulting in a sight adaptation lag (Jurado-Piña and PardilloMayora, 2009; Auffray et al, 2008; Jurado-Piña, Pardillo-Mayora and Jiménez, 2010; Yeung, Wong and Xu, 2013). So does this make older drivers more 
susceptible to crashing at or near tunnels? The logical response will be yes, but it is important to verify that this trend is accurate and that light contrast is the triggering factor.

The hypothesis of this study is that crashes tend to cluster in tunnel roads because older drivers cannot adapt their visions to the drastic change in lighting contrast. In other words, this study seeks to answer the question of whether crashes cluster along the area of influence of tunnels because older drivers are more likely to collide due to vision deficiencies. If so, what are the physiological factors that are triggering this phenomenon and what can transportation planners, transportation engineers and policy makers do to increase safety along tunnels, to increase traffic safety for the growing older population. This study analyzes the records of injury and fatal crashes from ten tunnels in California to determine if there is any evidence that supports the hypothesis that older drivers are more susceptible to crashes at the end of tunnels than those in other age groups.

\subsection{Relevance of Study}

Currently the US is undergoing a demographic transition with the babyboomer effect. This means that a large proportion of the population will be around 60 year or older, and this demographic shift has already started to occur as depicted in Figure 2. In addition to the ageing population, the average life expectancy is also increasing, which will increase the percentage of older drivers

on the roads (McKelvey, Maleck, Stamatiadis and Hardy,1988). It is important to 
identify if tunnel lighting constitutes a collision hazard to the ageing population, so the problem can be addressed in the design or retrofit of tunnels. Many of the safety tunnel audits focus on the road fixtures, such as shoulder widths, striping, signage and alignment. However, it is important to look at human factors, especially when there is evidence suggesting that human factors are exacerbated by changes in features along the road. 
Figure 2. Age Distribution Projections for California (2000-2030)

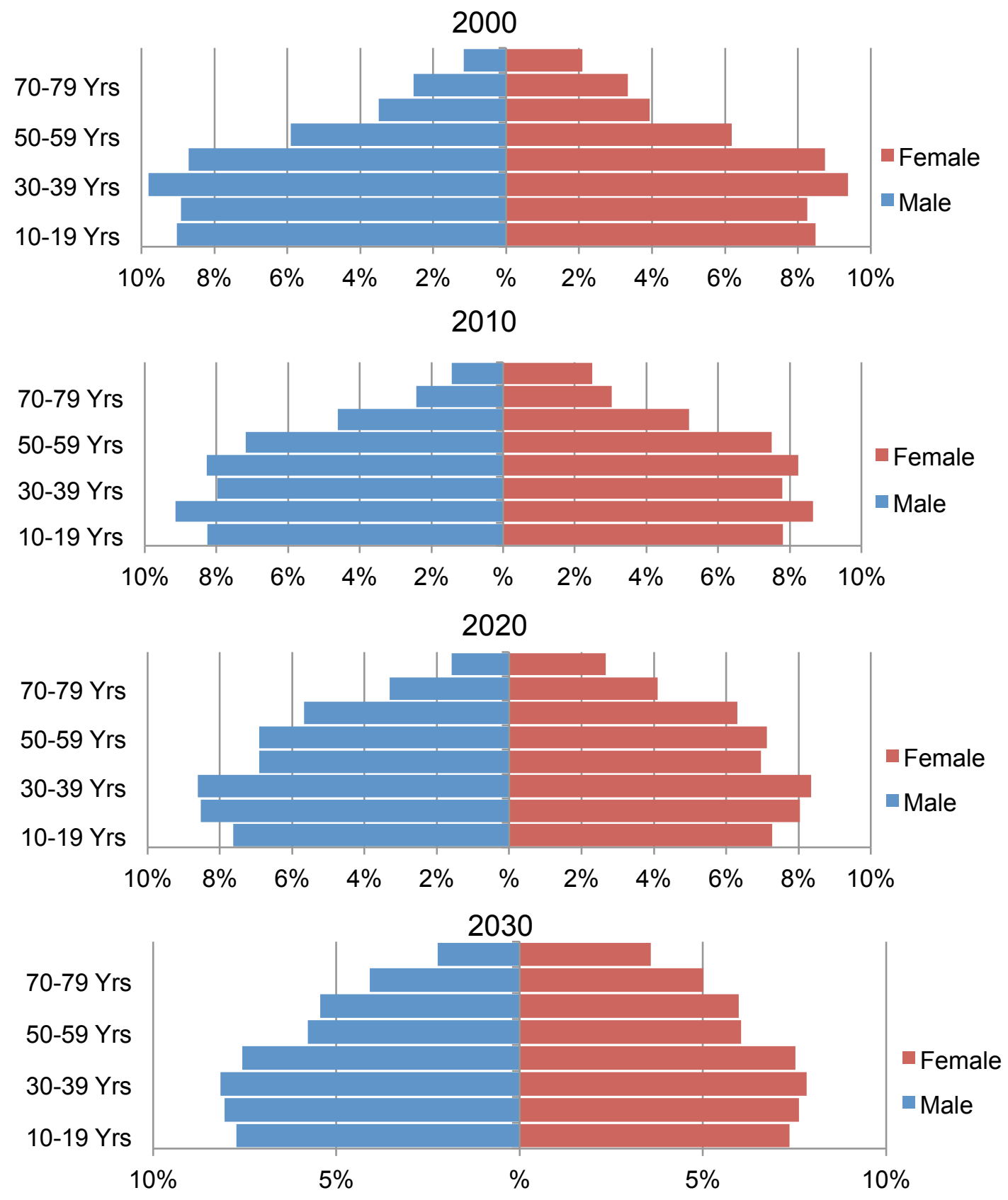

Source: U.S.Census Bureau, Population Division, Interim State Population

Projections, 2005. 


\section{LITERATURE REVIEW}

The literature review for this study provides background information that is used to establish a framework of physical and driver factors that are linked to tunnel crashes. For example, the premise of this study is that a driver's sight deteriorates with age, and this premise was validated with previous institutional, academic and medical studies that are found in the literature. Furthermore, the literature review provides insight of previous studies that have looked at tunnel crashes and have been successful in identifying significant triggering factors of open road and tunnel crashes. Significant trends were applied in the data analysis in order to identify if some of these factors are particularly influential in causing tunnel crashes.

The literature review also looked at existing policies and mitigation procedures that have been established in the State of California. Existing policies and procedures may be useful to explain potential inconsistencies between the literature review and findings of the data analysis.

\subsection{Physical Factors}

\subsubsection{Sunlight Glare}

Sunlight glare is a safety concern at the exit of tunnels and open roads in general because the glare caused by direct sunlight interferes with the driver's sight of the road (Jurado-Pina et al, 2010). This phenomenon is described as the "angle glare," the angle line between the driver's line of sight and the line direct to the sun (Jurado-Pina et al, 2010). Under sunlight glare conditions, driver's 
visibility of the road is reduced and low-contrast objects almost become invisible to the driver, and all of these conditions affect the driver's judgment of the traffic environment (Jurado-Pinta and Pardillo-Mayora, 2009). Factors that affect glare include:

1. Position of the sun relative to the driver's line of sight.

2. Direction of the driver's line of sight.

3. Configuration of the terrain.

Periods of sun glare have been associated with increased probability for crashes (Jurado-Piña and Pardillo-Mayora 2009). Traffic observations show that there is a reduction in traffic speed and an increase in vehicle headways during times of high glare (Jurado-Piña and Pardillo-Mayora 2009). Auffray, Monsere and Bertini (2008) also looked at sunlight glare and traffic flow and found that sun-glare has an influence on speed and flow distributions during congested and uncongested periods. A decrease in average vehicle speed suggests that drivers slow down to compensate for their vision impairment under sunlight glare conditions.

Mitra (2008) performed a study that looked at signalized intersections and crashes that had occurred during time periods of morning sun-glare, evening sun-glare and no sun-glare. The study looked at collisions in relation to directions, times of day and positions of the sun. As expected, findings supported the theory that the probability of crash occurrence can be correlated to sun-glare. 
Another study by Gray and Regan (2007) used a driving simulator to see performance at an intersection during low sun and where there was no sun-glare, and they found that low sun increased the risk of collision not only in vehicles, but in cyclist and pedestrians as well. Implicitly, the low-sun of the evening glare may also be more dangerous than morning glare, at the exit of tunnels.

Unsafe conditions due to sunlight glare are exacerbated in tunnels due to the added factor of light contrast adaptation lag that older driver's struggle with. There are equations that look at sun glare impairment as a function of the line of sight of the sun, the age of the driver and ocular pigmentation (Jurado-Pina et al, 2010). The threshold for glare impairment is found to be $19^{\circ}$ and $25^{\circ}$ for drivers in the ages between 40 to 60 years (Jurado-Pina et al, 2010). Driver's whose eyes are unable to rapidly adapt to high lighting contrast face an additional impairment in vision as they exit the tunnel and sunlight glare further their vision impairment. Gray and Regan (2007) found that older drivers are at a higher risk of crashing during low glare conditions, than younger drivers.

\subsubsection{Sunlight Glare Mitigation}

Sunlight glare is problematic to traffic safety, but there are road design techniques that can be implemented to mitigate this issue. To mitigate sun-glare it is important to determine the angle at which the sun-glare can impair a driver's performance; this condition is known as disability glare (Jurado-Pina et al, 2010). Terrain profile may serve to mitigate or exacerbate the effects of sunlight glare on drivers. It is important to determine if there are natural barriers obstructing sun glare at a tunnel's exit or if there are ways to obstruct glare. Forms of sunlight 
glare mitigation include the installation of sunlight shielding screens near tunnel exits (Jurado-Pina et al, 2010). Another mitigation technique it to install overhead sunlight screen and lateral screens. Lateral roadside barriers consist of objects such as trees or walls that shield the sun at tunnel exits (Jurado-Pina et al, 2010). However lateral barriers do not exist at every tunnel and depending on the angle of the sun and geometric configuration of the tunnel's exit, these barriers may not align properly to effectively block the sunlight glare.

\subsubsection{Lighting}

Lighting is one of the primary factors that affect drivers. A study that looked at driver's perspective in open road and tunnel expressways found that drivers perceived artificial lighting as impairment to their visual performance (Yeung et al, 2013). The State of California addresses tunnel lighting standard in the Traffic Manual, Chapter $9-10.5$, which state:

"Tunnels should have sufficient illumination during the day so that vehicles inside the tunnel may be seen by approaching motorists. All interior walls and ceilings of tunnels to be lighted should be painted or tiled in a light color. All concrete surfaces to be painted should have a Class 1 finish. Tunnels over $90 \mathrm{~m}$ long may require lighting in the daytime. Tunnels $30 \mathrm{~m}$ to $90 \mathrm{~m}$ long normally do not require daytime lighting but interior walls and ceiling should be painted. Conventional night lighting should be installed." (www.dot.ca.gov, 2006).

These design guidelines provided the basic standards of tunnel lighting, but there are other factors that are not fully considered. The factors include lighting contrast and glare under certain conditions and time of day. 


\subsubsection{Flickering and Rhythmic Lighting}

Photic stimulation is defined as the adverse neurological effect of flickering or rhythmic lights (Janoff, 1988). The illuminating Engineering Society found that effects of flickering lights cause sensations of dizziness, drowsiness, queasiness, or hypnotic states in motorists. At night, photic stimulation could lead to an increase in collisions because contrast and flickering effect become more prominent. A study on the San Mateo Bridge showed that increase in collisions was influenced by lineal lighting after 3 minutes of exposure, replacement of this type of lighting showed an improvement (Janoff, 1988).

\subsubsection{Ventilation}

Ventilation in tunnels is important in reducing the risk and severity of tunnel fires (Zhang and Ma, 2006). However, ventilation of tunnels also functions to dissipate smog clouds formed by vehicle exhaust. Smog absorbs the light formed by tunnel lighting devices and vehicle headlights, and form a scattering light phenomenon, and this condition decreases visibility, which reduces driver's performance (Zhang and Ma, 2006; Wu, Lin, Pin and Tsui, 2012). Tunnel ventilation for small tunnels can be provided by natural means, whereas longer tunnels require mechanical ventilation systems that vary according to tunnel setting, length and code requirements. 


\subsection{Human Factors}

Traditional practices of assessing traffic safety have focused on vehicle and road dynamics, while human factors are given little consideration. Human factors and human error are the primary collision factors in the majority of crashes. Thus, it is important to identify if the human errors that can be mitigated with road design and/or physical fixtures.

\subsubsection{Age}

For years, transportation statistics have associated younger and older driver populations as being at fault for a high proportion of crashes. McKelvey et al (1988) claim that drivers between the ages of 17 to 19 years old are three times more likely of being involved in a traffic collision than drivers of age 65 and older. Younger drivers are believed to be more at risk of crashing due to factors of inexperience and behavior. Cohen, Dearnaley, and Hansel (1958) claim that younger drivers are more prone to crashing because they take on more and higher risks while driving. Cohen et al (1958) define high-risk behavior as the act of performing a driving maneuver without the certainty of a successful outcome. However, due to fragility and physical impairments that come with age, older drivers are at a higher risk of being involved in a fatal or severe injury collision. Because most jurisdictions only record injury or fatal collisions, older drivers can also be overrepresented in traffic collisions and be depicted as more at risk than younger drivers. This study only takes into account injury and traffic collisions, so it is expected that older drivers may be overrepresented in the data set. 


\subsubsection{Crash Severity}

Older drivers are associated with being involved in a higher number of fatal and injury collisions due to frailty. The literature suggests that sensory, perceptive and cognitive abilities deteriorate with age, paired with physical medical conditions; older drivers have a higher risk of crashing (Griffin, 2004). According to the AAA foundation, drivers of age 65 are 1.78 times more likely to die in collisions, than drivers' ages 55 to 64 . Furthermore, drivers over 75 and 85 years old were 2.59 and 3.71 more likely to crash, respectively, than other age groups (Washington and Sosseh, 2004). Peter Kissinger, the President of the AAA Foundation for Traffic Safety states that "our eyesight deteriorates to such an extent that by age 60 we require ten times the amount of light necessary to see an object as when we were 16" (Washington and Sosseh, 2004).

\subsubsection{Driving Behavior and Performance}

There are positive and negative aspects of young and older drivers' driving behavior. There are conflicting claims that suggest that older drivers pose a hazard to the road due to their sub-optimal ability to drive due to physical impairments, such as vision, mobility and delay in reaction and response. On the other hand, older drivers are also thought of as having more precautionary driving habits. This claim is based on the average speed at which different age groups tend to drive. On average, older drivers drive slower than younger drivers and this is attributed to being precautious. Horberry, Anderson, Regan, Triggs and Brown, (2006) performed a study that looked at how distracted drivers reacted to the sight of a hazard based on three different age groups. This study 
concluded that older drivers' mean speed is significantly lower than all other age groups as shown in Table 1. It is unclear if these results indicate that older drivers are more precautious while driving, or if older drivers drive slower to compensate for their physical impairments. As opposed to older drivers, young drivers are often thought of as being engaged in riskier behavior, due to immaturity and inexperience (Cohen et al, 1958).

Table 1. Mean Minimum Speed (km/h) Reached During Hazard.

\section{Age group Minimum speed}

\begin{tabular}{r|l|}
\hline Under 25 years & $32.46 \mathrm{Km} / \mathrm{h}$ \\
\hline $30-45$ years & $17.23 \mathrm{Km} / \mathrm{h}$ \\
\hline Over 60 years & $11.76 \mathrm{Km} / \mathrm{h}$ \\
Source: Horberry et al (2006)
\end{tabular}

However, younger drivers are also thought of having better vision and physical movement abilities that would make them more likely to react and respond in a timely manner to the sight of a hazard. Rogé and Pébayle (2009) found that young drivers performed better than older more experienced drivers in a simulated driving study that tested the driver's ability to detect peripheral road information. Rogé and Pébayle (2009) suggest that driving experience does not compensate for adequate vision, so young drivers performed better than older drivers under experimental conditions. This implies that younger drivers' overrepresentation in traffic collisions may be attributed to factors that are more dangerous than deficiencies driving experience. The factors may include highrisk behavior and driving under the influence. Again, it is important to reiterate 
that these findings are derived from controlled experiments, which may influence behavior and exclude high-risk behavior.

\subsubsection{Vision}

Vision is the primary sense use while driving. According to $\mathrm{Li}(2000)$, of the sensory organs used when driving, vision accounts for $80 \%$ and hearing accounts for $14 \%$. Song and Yang, 2009 , claim that $80 \%$ of the information obtained by drivers is through their eyes. This suggests that deficiencies in vision can hinder driver's performance, exposing them to a greater risk of crashing. The premise of this claim reflects how important it is for drivers to have optimum sight to be able to safely operate a vehicle.

Vision is the primary sensory factor in driving performance, and it deteriorates with age, affecting older motorist in their driving performance. Tunnels exits are particularly hazardous because there is a transition from bright to dark conditions at night or dark to light condition during the day. The human eye is required to adjust during the transition of light to dark environments, this process in known as light adaptation. Du, Pan, Yang, and Guo (2007) describe these phenomena as visual turbulence at tunnel entrance and exit, which reduced drivers' stopping sight distance. Wolfson and Graham (2000) and Tasman and Jaefer (2004) claim that it takes the human eyes about three seconds to adjust and begin to distinguish low contrast objects. There are several factors that reduce the ability of an individual's eyes to quickly adapt to lighting changes, and age is one of these factors. 


\section{Vision Deterioration}

The useful field of sight deteriorates with a driver's age, which leads to tunnel vision (Rogé and Pébayle, 2009; Ball et al., 1988; Scialfa, Kline and Lyman, 1987a; Sekuler and Ball, 1986). Multiple studies have concluded that a driver's ability to detect peripheral signals in a dual task decreases with age, to varying degrees (Rogé and Pébayle, 2009). In a controlled experiment, younger drivers performed better than older drivers, and the gap in performance increases when signals are off-centered, causing older drivers to miss road information. Kline D., Kline T., Fozard, Kosnik, Schieber and Sekuler, 1992, performed an experiment that looked at the driving performance of drivers ranging from 22 - 92 years old. Kline et al, 1992, found that since vision deteriorates with age, it affects older drivers in the following visual dimensions: unexpected vehicle speed, dim displays, windshield problems and reading signs. Furthermore, Kline et al, 1992, state that visual processing speed, light sensitivity, dynamic vision, near vision and visual search also deteriorates as a function of age.

The eye has two types of photoreceptor cells, the cone cell and the rod cell; the difference between the two is the speed at which they receive light (Zhao et al, 2011). The cone cell is at the center of the retina and is the photoreceptor of bright light (Zhao et al, 2011). The rod cell is in the circle of the retina and is the photoreceptor of dark vision (Zhao et al, 2011). When the driver enters a dark environment, the rod cell adapts, as the environment transitions to a brighter

environment, the retina adapts. When exiting a tunnel, dark-to-light or light-to- 
dark transition is rapid, and the cognitive and eye reaction of the driver lags. This poses a great hazard for older drivers, especially in the light dynamics encounter in a tunnel environment.

\section{Visual Fixation}

Visual fixation is the act of maintaining visual gaze at the same location with alternating saccades or small movements of the eyes. The duration of visual fixation and saccades, along with pupil diameter, can be indicative of a driver's visual behavior, and "visual behaviors [can] accurately evaluate the traffic environment's safety" (Du, Huang and Pan, 2013). There have been many studies that use visual fixation to assess safety in tunnel and roads. Du, Pan and Guo, 2008, looked at the variation of pupil area to evaluate safety at tunnel entrance and exits. Shi Ludan, 2011, used five indexes of eye fixation behavior in long freeway tunnels to analyze fixation area (Du et al, 2013). Visual fixation is used to assess tunnel safety because it indicates where the drivers are looking and the potential for them to miss surrounding information.

Visual fixation is also a function of what Mackworth (1965) defines as useful visual field, which is the information around the fixation point that is stored and processed during a visual task. Rogé and Pébayle (2009) defines the useful visual field as the "peripheral visual field around the fixation point inside which sources of information can be processed at a single glance" with no eye or head movement. Due to sight deterioration with age the ability of drivers to capture and process peripheral information such as road signage decreases. A driver with an impaired useful visual field has similar effect to increasing vehicle speed because 
both factors can lead to tunnel vision Rogé and Pébayle (2009). Note that tunnel vision is a hazard, even in a tunnel setting because drivers may become unable to detect signage, or more importantly, parallel cars engaging in risky behavior like merging or unsafe lane changing. Rogé and Pébayle (2009) found that young drivers performed better than older more experienced drivers in a simulated driving study that tested the driver's ability to detect peripheral road information. This suggests that when it comes to visions, driving experience does not compensate for adequate vision. Again, these findings suggest that younger drivers' overrepresentation in traffic collisions may be attributed to factors that are more dangerous than deficiencies in vision.

Du et al (2013) performed a study of eight subjects driving in four different tunnels and each tunnel was segmented into seven different sections. The study concluded that "visual load" at tunnel exists and entrances are heavier than at the middle of tunnels, making drivers prone to missing road information along the tunnel. In another study, Zhao and Liu (2011) also concluded that drivers' visual fixation duration is lower at the entrances and exits of tunnels and recommends that road signs and markings be placed in the range of drivers' eye fixation.

Visual fixation can be in response to other physiological and psychological factors exerted on the driver, such as mood, age, driving habits, etc. Du et al (2013) warns that visual fixation distribution while driving through a tunnel is not sufficient to determine whether a highway tunnel is safe or not. However, visual fixation has been effective in studies looking at drivers' behavior in tunnels, these studies report that a driver's visual fixation decreases in duration and "visual 
load" increases at the entrance and exit of tunnels Rogé and Pébayle (2009). This reaction may be due to the environmental turbulence drivers experience at the entrances and exits of tunnels. Any type of turbulence that raises drivers' visual alertness may serve to make them aware of signage and marking, but this increase in visual alertness can also be an indication of tension, in which case it would increase the risk of being involved in a collision.

\section{State of California Vision Requirement}

The State of California requires that every person pass a vision test before issuing them a driving license to enhance road safety. The DMV's screening standards require a person to be 20/40 with both eyes together, and 20/40 in one eye and at least 20/70 in the other eye. As stated in the guide, (Vision Standards (FFDL 14) - Visions Requirements for Driving Class C Vehicles, 2011) the test evaluates a person's:

- Vision condition.

- Vision conditions affecting central and side vision.

- Whether vision condition affects one or both eyes.

- If vision condition can be corrected with glasses, contact lenses or surgery.

- Whether vision will continue to deteriorate. 
If a person cannot fully satisfy a vision test, the DMV can issue a driver license under certain restrictions. The DMV will typically impose a driving restriction for senior drivers based on vision-related concerns, which may include anything that the DMV considers to be unsafe according to the physical condition of the individual. Examples of driving restrictions to senior drivers relating to visions deficiency include (www.dmv.ca.gov, 2011):

- No freeway driving

- An additional right side mirror on the vehicle

- Daylight driving only

- Specific time of day driving only, which may include, to not drive during rush hour

- Area restriction

- Wearing sight-aiding devices such as a bioptic telescopic lens

However, the Department of Motor Vehicles (DMV) states, "impaired vision will not usually prevent you from obtaining a driver license if you can show that you are able to drive safely" (Vision Standards (FFDL 14) - Visions Requirements for Driving Class C Vehicles, 2011). This policy allows for drivers with complex visual impairments to drive. Driver's who suffer from sight impairments that are only problematic under certain environments, during 
nighttime for example, would be able to obtain a driver's license under the State of California's current visions requirements to issue a license. Even though this policy states that drivers have to show that they are able to drive safely, the vision test is administered under room conditions and does not include conditions that could drastically alter a driver's vision, like drastic change in lighting.

There is the possibility that the DMV will issue driving licenses to drivers with vision impairments. If the person is unable to pass the test administered by the DMV staff, they are referred to a vision specialist to have a Report of Vision Examination (DL62) and prove that their vision is adequate to operate a vehicle, and pass a driving test that "establishes that you can compensate for any vision loss caused by your vision condition" (Vision Standards (FFDL 14) - Visions Requirements for Driving Class C Vehicles, 2011).

The DMV requires drivers with sight restrictions to pass a vision test, but reexamination for license renewal is not a uniform standard across all drivers and some drivers are eligible for mail or online license renewal. However, drivers can take personal responsibility for their vision competence and self-assess their ability to drive; the DMV has published a guide of Physical and Mental Condition Guidelines. This guide lists a series of vision conditions that can impair driving performance, possible solutions to mitigate the problem, and recommended actions according to severity (Vision Standards (FFDL 14) - Visions Requirements for Driving Class C Vehicles, 2011). 


\subsubsection{Physiological and Psychological Factors}

\section{Tension and Claustrophobia}

It is important to account for human reactions to tunnel because nervousness and tenseness exacerbate the risk of crashing. Tension makes drivers prone to perform drastic movements that can lead to a crash. A typical behavior in a driver's response to the tunnel is the urge to exit, making them more prone to missing information along the tunnel (Evans et al, 1984; Yeung et al, 2013) and along their peripheral vision. Tension in drivers can be measured by increased heart rate and enlargement of the pupil's diameter. Zhao et al (2011) conducted a study where they measured eye tracking together with a multiple parameter detector that measured pupil and heart rate as the driver traveled along a tunnel and found that heart rate and pupil dilation increases on tunnel roads, which is an indication of tenseness and nervousness.

Yeung et al (2013) found that drivers are more likely to obey speed limits and maintain larger gaps in tunnel roads than in open roads. This traffic behavior is associated with the driver's perception of danger in tunnels. Tunnels may produce a feeling of "insecurity and riskiness inside the tunnels, possible attributed to elements of claustrophobia. Enclosed spaces, entrapment, darkness and a lower level of perceived control are said to induce fear and avoidance of

underground spaces" (Yeung et al, 2013). The perception of risk in a tunnel may explain why younger drivers have higher crash rates, as they are associated with 
having a higher tolerance for what they perceive as risky behavior. The perception of risk in a tunnel may have a positive effect on safety because precautious driving may serve as a defense mechanism in some drivers.

Drivers may also develop an urge to exit the tunnel due to claustrophobia, which makes them more likely to increase their velocity as they exit the tunnel. For example, during a tunnel collision, other drivers' response is to exit the tunnel rather than to take refuge on the "clearly indicated shelters provided inside the tunnel" (Marec, 1996). Suggesting that rushing to the tunnel exit is a safetyseeking behavior, as many drivers perceive tunnels with a negative connotation. Groenhaug (1997) states that the close environment of the tunnel gives drivers a sense of depression making them want to leave the tunnel in a hurry. Thus, the driver becomes bored or depressed with its monotonous surroundings and focuses attention on the end of the tunnel since it becomes an immediate objective to get out (Zhao and Liu, 2011).

It would be expected that frequent drivers of tunnels or the same tunnel would develop indifference to this type of driving environment, while infrequent users would be more likely to exhibit a significant psychological or physiological reaction. However, Yeung el al (2013) found that familiarity with a tunnel does not affect a person's perception of tunnels.

In summary, what the literature tells us about driver's physiological and psychological response to tunnels is that it varies on an individual basis; some 
drivers feel the urge to exit and speed, while other drivers compensate the feel of danger by slowing down. The non-uniform response of drivers as it pertains to speed may led to rear-end collisions. 


\section{STUDY METHODOLOGY}

Crash data of ten tunnels in California was used to test collision trends identified in the literature review. This chapter discusses the methodology that was used in analyzing the injury and fatal crash data, which includes data source, framework and site selection.

\subsection{Data}

\subsubsection{Data Source}

To examine the relationship between driver's age and their likelihood of being involved or causing a collision at the entrance or exit of a tunnel, data from the California Highway Patrol - Statewide Integrated Traffic Records System (SWITRS) was used. The data was retrieved via the Transportation Injury Mapping System (TIMS); the University of California, Berkeley, runs this site and it uses Geographical Information Systems (GIS) software to map collisions reported by SWITRS into a map. This data can be queried by location and the crash records are divided into three categories, which provide the following collision information in Table 2. 
Table 2. Information Provided in Crash Records

Collision

Parties

Victims

\begin{tabular}{c|c|c|}
\hline Location & Number of Parties Involved & Victim Role \\
\hline Time & Party at Fault & Age \\
\hline Date & Sex & Sex \\
\hline Collisions Type & Direction of Travel & Degree of Injury \\
\hline Number of Parties & Collision Factors & Victim Ejected From \\
Involve & & Vehicle \\
\hline Road Conditions & Violation Category & Sobriety \\
\hline Involve with & Cell phone use & Passenger type \\
& & \\
\cline { 2 - 3 } & &
\end{tabular}

Data source: Traffic Injury Mapping System (TIMS), Safe Transportation

Research and Education Center (SafeTREC), University of California, Berkeley. 2013

The TIMS GIS mapping tool allows users to query spatial collision information by city and county geographies. Collisions that occurred on state highways can be filtered, but will only depict the segment within the selected city or county. Collision information for this study was collected using the buffer circle and selection feature that enables the selection of collisions within $1 / 4$ mile from the extremities of the tunnel. All of the accidents falling within the circle radius in 
the area and direction of interest were downloaded in two different Excel format files, by collision records and parties' records. Collisions that occurred within $1 / 4$ mile from the tunnel's extremities, but also lay at or past a ramp or intersection were excluded. Ramp and intersection collisions were not included due to the overlapping effect that this may have on crash influence. Unless a detailed investigation of each collision was assessed, it would have been challenging to attribute these crashes to tunnel related factors and not the ramp or intersection, and the goal was to only look at collisions associated with tunnels.

\subsubsection{Data Limitations}

The documentation of crashes is extremely useful to identify hotspot areas and to determine how road, vehicle and driver factors influence collisions. Once a safety problem has been identified in regards to geographical location or driver characteristics, the jurisdiction in charge can take action in addressing the problem. However, Mason (1992) claims that data of the police reports is not always reliable due to inconsistencies in coding, accident configuration and vehicle identification, etc. The cause or primary factor of collisions is likely to be miscoded if an at-length investigation is not performed. For example, rear-end collisions may be caused by following too closely, unsafe speed or both.

However, in order to reduce complexity in the reporting of the data, police reports usually select only one. Although there is room for error in the collision data, this error may also be marginal and these reports can still be useful for discerning general crashing trends. 
When looking at the data, it is important to recognize that this dataset is not reporting Property Damage Only Collisions. It only looks at collisions where one of the parties has been injured or died. Older drivers are more likely to be involved in a fatal or injury collision due to fragility, so it is possible that older drivers are over-represented on this data set.

One of the main limitations of the data set is that of 968 collision records, 72 did not have the age of the driver and it was marked as unknown, possible as a result of hit and run type collisions. This accounts for more than seven percent of the data and would have resulted in more accurate results if all the collisions had been accounted for in the age distribution analysis. There were also inconsistencies in coding of information or there was missing information altogether. There were duplicate records of collisions with the same identification number, but conflicting information, in the type of crash and which party were at fault, so these collisions were excluded from the study.

\subsection{Analytic Framework}

The literature review suggests that vision deteriorates with age, and vision is the key to optimal driving performance. One of the primary functions of vision that gets affected is the eye's ability to quickly adapt to the light contrast. Tunnel exits create an environment where drivers have to quickly adapt to lighting two times, (exit and entrance) in a short period of time. From this claim, it can be deduced that older drivers are prone to collide at the ends of tunnels. To verify this assumption, ten year (2002-2011) collision records of ten tunnels in Northern and Southern California that included collision and driver information were 
analyzed to study the relationship between age proportion cohorts and crash characteristics in graphical or tabular form. Most of the age related information was plotted based on location, to determine if the older drivers had a higher crash frequency at the end of tunnels. Any suspected association of age and crash characteristics was tested for statistical significance using a Chi-Square test. A Lorenz Curve and Gini coefficient were computed to measure the distribution inequality between age proportions compared to crash proportion for age cohorts.

\subsubsection{Site Selection}

The study site were selected to be 0.25 or less miles from the tunnel exit or entrance and along the tunnel because, as Wolfson and Graham (2000) and Tasman and Jaefer (2004) suggest, it takes the human eyes about three seconds for the eyes to adjust and begin to distinguish low contrast objects. Assuming an average speed of 60 miles per hour, drivers would have traveled 0.05 miles under normal sight conditions, thus drivers whose vision is lagged, could have crashed after traveling 0.05 miles.

The tunnels selected for this study are all in the State of California and includes tunnel in cities and along state highways. These tunnels were chosen based on collision frequency and simple geometry. In other words, the tunnel had to include more than 10 crash records, per the ten-year period and could not have been under the influence of other complex setting, like a ramp interchange. 


\subsubsection{Tunnels}

Figure 3 identifies the locations of the ten tunnels studied. This section outlines their physical characteristics while crash and operating characteristics are listed in Table 3.

Figure 3. Tunnel Locations

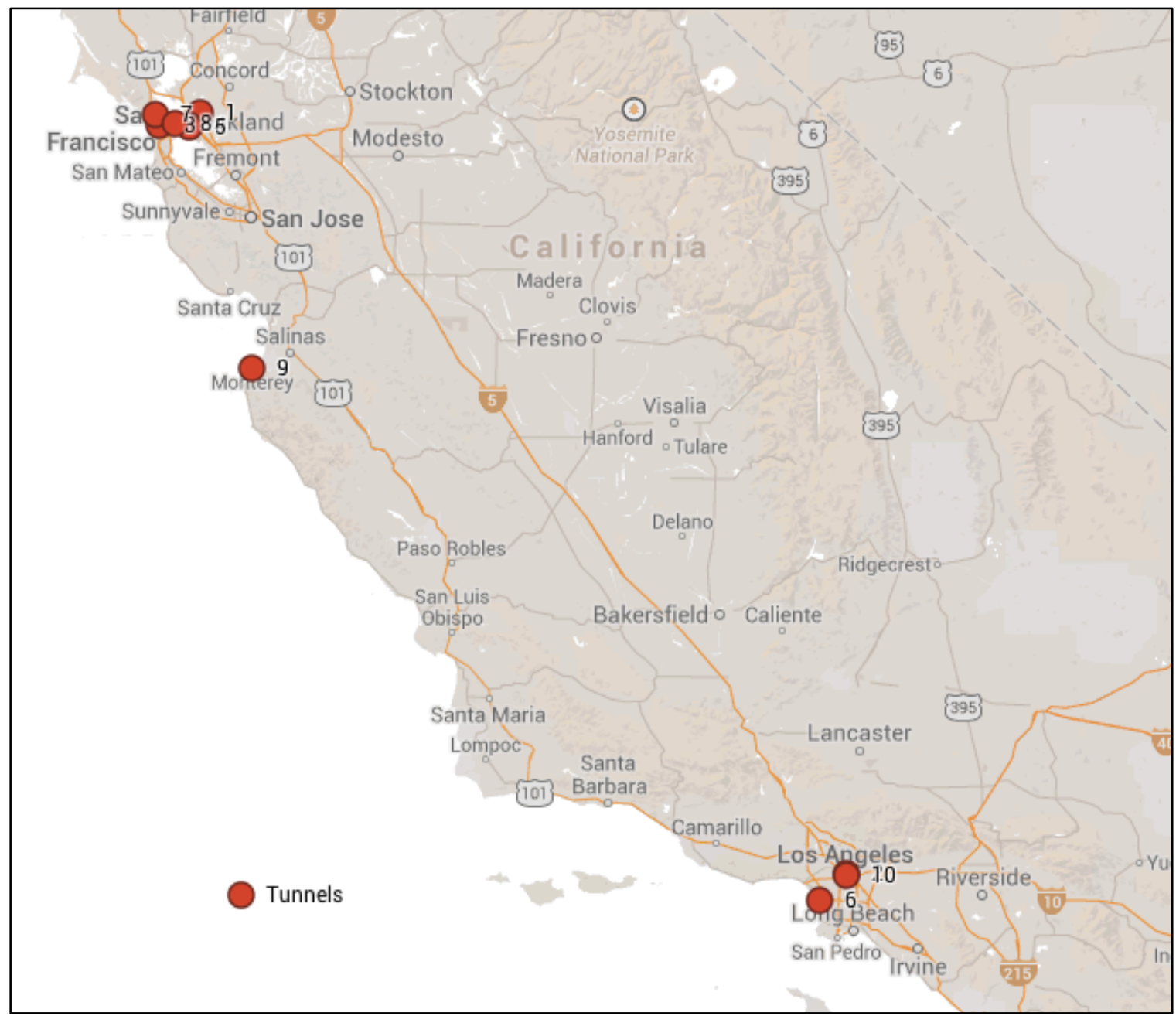

Source: Map Data @ 2014 Google, INEGI

\section{Caldecott Tunnel}

- Location: CA 24, between Orinda and Oakland. 
- Direction: east and west.

- Number of lanes: two in each direction.

\section{Figueroa Street Tunnels}

- Location: CA 110, westbound only, Los Angeles.

- Direction: west.

- Number of lanes: two in each direction.

- Additional: one-way westbound, at the north 0.25 mile right before then it crosses the $1-5$.

3. MacArthur Tunnel

- Location: CA 1, San Francisco.

- Direction: north and south.

- Number of lanes: two in each direction.

- Additional: posted speed limit at the tunnel is $\mathbf{4 5}$ miles per hour.

4. Posey Street Tube

- Location: SR 260 \& SR 61, Oakland. 
- Direction: east.

- Number of lanes: two lanes in one direction.

- Additional: posted speed limit at the tunnel's entrance is 45 miles per hour.

5. Webster Street Tube

- Location: SR 260 \& SR 61, Oakland.

- Direction: west.

- Number of lanes: two lanes in one direction.

6. Sepulveda Boulevard Tunnel

- Location: CA 1, Los Angeles California

- Direction: north and south

- Number of Lanes: three lanes in each direction

- Additional: Beneath International airport LAX, NE was measure at the intersection of World Way $S$ at less than $1 / 4$ mile ( 0.2 miles) exactly because the nature of the road changes and it became complicated to discern patterns. SW was cut at 0.2 miles at the intersection of the $\mathrm{I}-105$ because the road changed character 
7. Waldo Tunnel

- Location: US 101 and CA1, Sausalito.

- Direction: north and south.

- Number of lanes: four to five in each direction.

8. Yerba Buena Tunnel

- Location: I-80, Yerba Buena Island in San Francisco.

- Direction: east and west.

- Number of lanes: five in each direction.

- Additional: Middle of San Francisco-Oakland Bay Bridge. A twolevel bridge tunnel.

9. Lighthouse Ave Monterey Tunnel

- Location: City of Monterey.

- Direction: north and south.

- Number of lanes: two in each direction. 
10. Cesar E Chavez Tunnel

- Location: City of Los Angeles.

- Direction: east and west.

- Number of Lanes: two to three in each direction. 
Table 3. Tunnel Characteristics (2002-2011)

\begin{tabular}{|c|c|c|c|c|c|}
\hline Tunnel & Length (miles) & Crash count & AADT & Crash / year & Crash rate \\
\hline 1. Caldecott & 1.38 & 176 & 154000 & 17.6 & 0.23 \\
\hline 2. Figueroa St & 1.29 & 210 & 163000 & 21 & 0.27 \\
\hline 3. McArthur & 0.6 & 21 & 60000 & 2.1 & 0.16 \\
\hline 4. Posey & 0.13 & 5 & 22300 & 0.5 & 0.47 \\
\hline 5. Webster & 0.75 & 15 & 22300 & 1.5 & 0.25 \\
\hline $\begin{array}{r}\text { 6. Sepulveda } \\
\text { Blvd }\end{array}$ & 0.71 & 35 & 77000 & 3.5 & 0.18 \\
\hline 7. Waldo & 0.67 & 52 & 104000 & 5.2 & 0.20 \\
\hline 8. Yerba Buena & 0.65 & 376 & 122000 & 37.6 & 1.30 \\
\hline $\begin{array}{r}\text { 9. Lighthouse } \\
\text { Ave }\end{array}$ & 0.55 & 13 & 51936 & 1.3 & 0.12 \\
\hline $\begin{array}{l}\text { 10. Cesar E. } \\
\text { Chavez Ave }\end{array}$ & 0.06 & 17 & 20310 & 1.7 & 3.82 \\
\hline \multicolumn{6}{|c|}{${ }^{a}$ AADT - Annual Average Daily Traffic } \\
\hline
\end{tabular}

The crash rate of each tunnel was computed to explore in Table 3 to determine the degree to which each site differs in terms of crash count, Annual Average Daily Traffic, Crash rate per Million Vehicle Miles Traveled (MVMT) and the length of the segment studies. The Cesar E. Chavez tunnel had the highest injury crash rate with 3.82 crashes per MVMT. The Lighthouse Avenue tunnel had the lowest crash rate of 0.12 crashes per MVMT. It is important to note that 
crash rate is only slightly indicative of how safe a road is because there are several limitations to the formula's underlying assumptions. Crash rate assumes a linear relationship between AADT and crashes per MVMT.

\subsubsection{Age Cohorts}

This study uses demographic information of age and gender from the American Community Survey for the metropolitan area of Los Angeles and San Francisco. For this study the combined average of the age-cohort proportions of both areas was used because, as shown in Figure 4, the proportion of age distribution is similar between Los Angeles (LA) and the San Francisco Bay Area (Bay Area).

Figure 4. Age Distribution (2010)

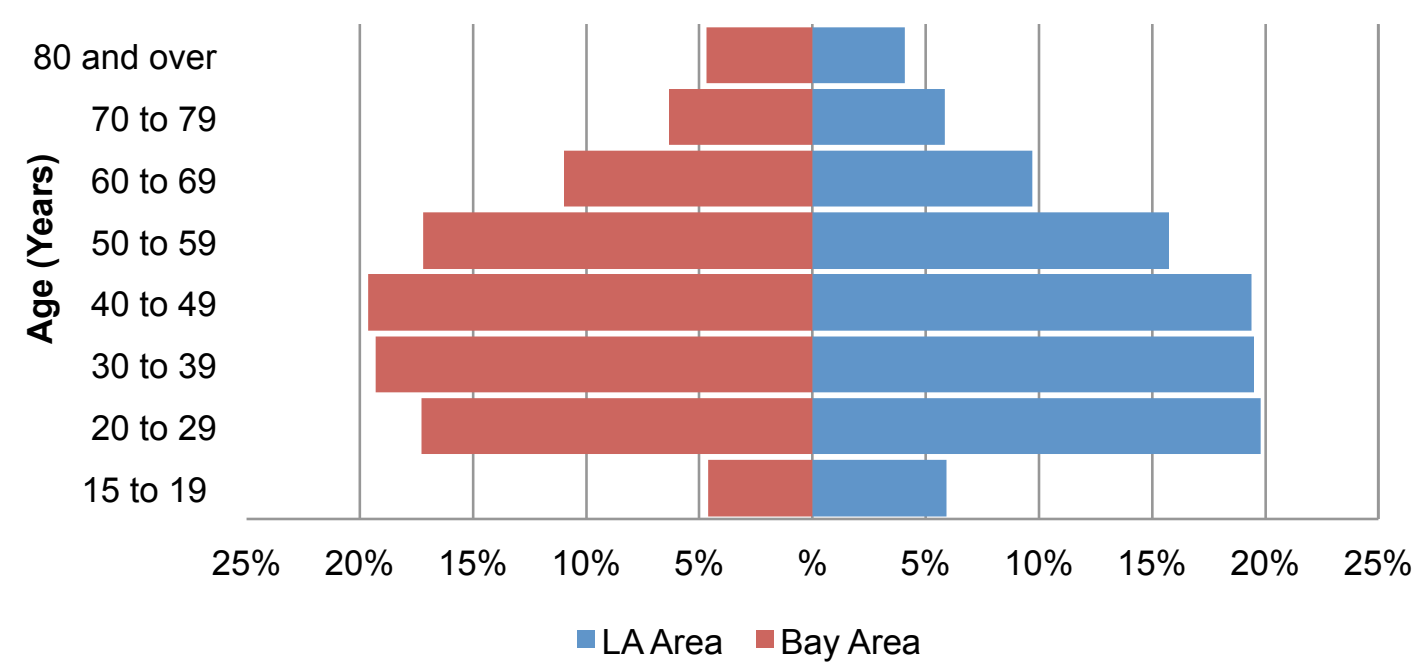

Source: QT-P1-Geography-California: Age Groups and Sex: 2010, Tables P12, P13 and PCT12. 2010 Census Summary File 1. 


\subsubsection{Age Cohort Determination}

In order to compare how deterioration of vision in the older population affects tunnel safety, the elderly group had to be compared to the young and middle age population. When describing general patterns of collisions characteristics all ages are included. This age distribution was adopted from Horberry et al (2006) because it eliminated the continuity in age distribution and this helps to better separate and compare young, middle age and older drivers. However, in the statistical analysis test, collisions were broken down into five different age groups: under 25 years, $26-29$ years, $30-45$ years, $46-59$ years and 60 and over. 


\section{ANALYSIS AND RESULTS}

This chapter provides the findings of the tunnel injury and fatal crash data that was analyzed to test crash factors identified in the literature review. Since this study focuses on discerning crash patterns that relate tunnel crashes to ages of drivers, the data analysis is directed towards identifying trends affecting older drivers and how these differ from drivers of younger ages. Findings and trends are depicted in graphical and tabular form, and chi-square tests were applied to relevant sections. A Lorenz Curve and the Gini coefficient were used to study population proportions and provide an indication of the extent to which population proportions are unequally distributed in the crash data.

\subsection{Expectations}

The literature review makes claims that accidents cluster at tunnel openings and that they are particularly dangerous to older drivers as they change environment in lighting. However, I have not been able to find a study in California that looks at collisions that support this claim. Given this premise to be true, one would expect to see an over representation of older drivers in traffic collisions at tunnel openings.

Where relevant a chi-square test was applied to test if the relationship between age and some other factor was statistically significant. Statistical significance means that it would be extremely unlikely for a certain distribution to occur if the two variables were independent. If the alpha level is smaller than .05 , 
then you accept the null hypothesis stating that there is a relationship between the two variables, meaning that an " $X$ " factor is dependent on age.

\subsection{Crash characteristics}

\subsubsection{Temporal Distribution}

\subsubsection{Yearly}

Figure 5 shows the yearly crash distribution from the year 2002 to 2011 for all tunnel locations. The average crash count is 97 crashes per year. The range of lowest and highest recorded crashes occurred in 2011 and 2007, with 82 and 109 crashes, respectively. Even though the last two years of data have the lowest recorded crash counts, this does not constitute an improvement in safety conditions because crashes are random events and yearly variation is expected.

Figure 5. Yearly Distribution of Crashes (2002-2011)

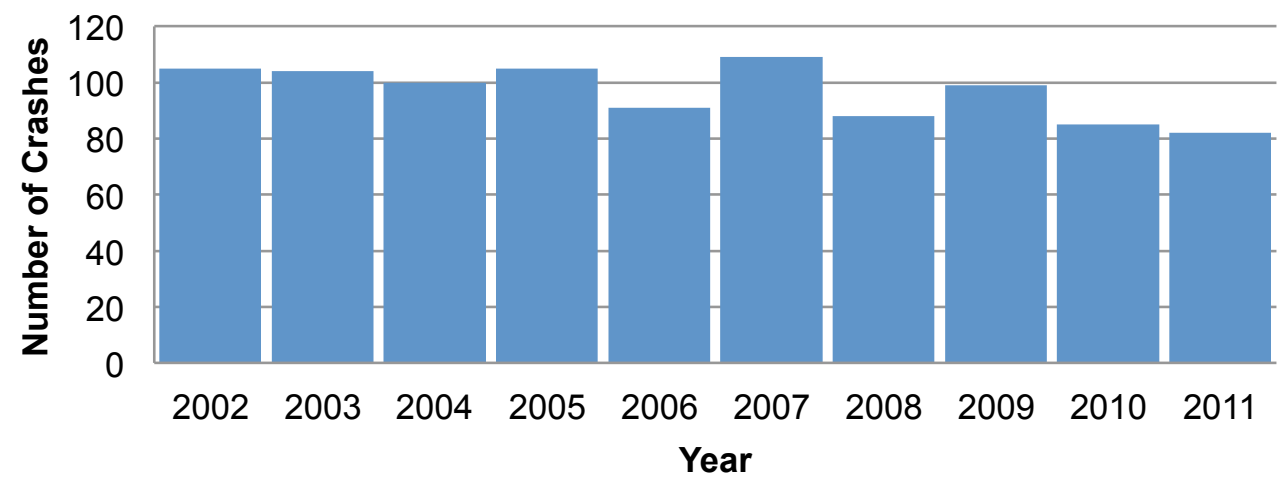

Data source: Traffic Injury Mapping System (TIMS), Safe Transportation Research and Education Center (SafeTREC), University of California, Berkeley. 2013. 


\subsubsection{Monthly}

The monthly distribution for all the recorded injury accidents at the ten tunnels is shown in Figure 6.The monthly distribution is relatively consistent with DeGroat's (2009) claim that October is the month with the most recorded collisions. All months account for roughly six to ten percent of all crashes, the highest counts are recorded in the months of August and October with 99 and 92 crashes, respectively. January had the lowest crash count with 65 crashes.

A study from an insurance company, State Farm, revealed that October had the highest crash rate for teens, which may be due to higher incidence of alcohol consumption (State Farm, 2013). DeGroat (2009) also states that a study performed by the University of Michigan Transportation Research Institute calculated that crash rates are highest in the fall, again with October at the top. There are no concrete factors that would explain the high crash frequency during the fall, plausible explanations have been longer dark periods, but this theory remains unsupported.

Similarly, Mitra (2008) state that there is statistical evidence suggesting the early spring and early fall evening glare is worst to traffic safety, and to a lesser degree in summer times. The monthly crash distribution in Figure 6 does not support or reject this claim due to randomness and the complexity of factors that are associated with crashes. 
Figure 6. Monthly Distribution of Crashes (2002-2011)

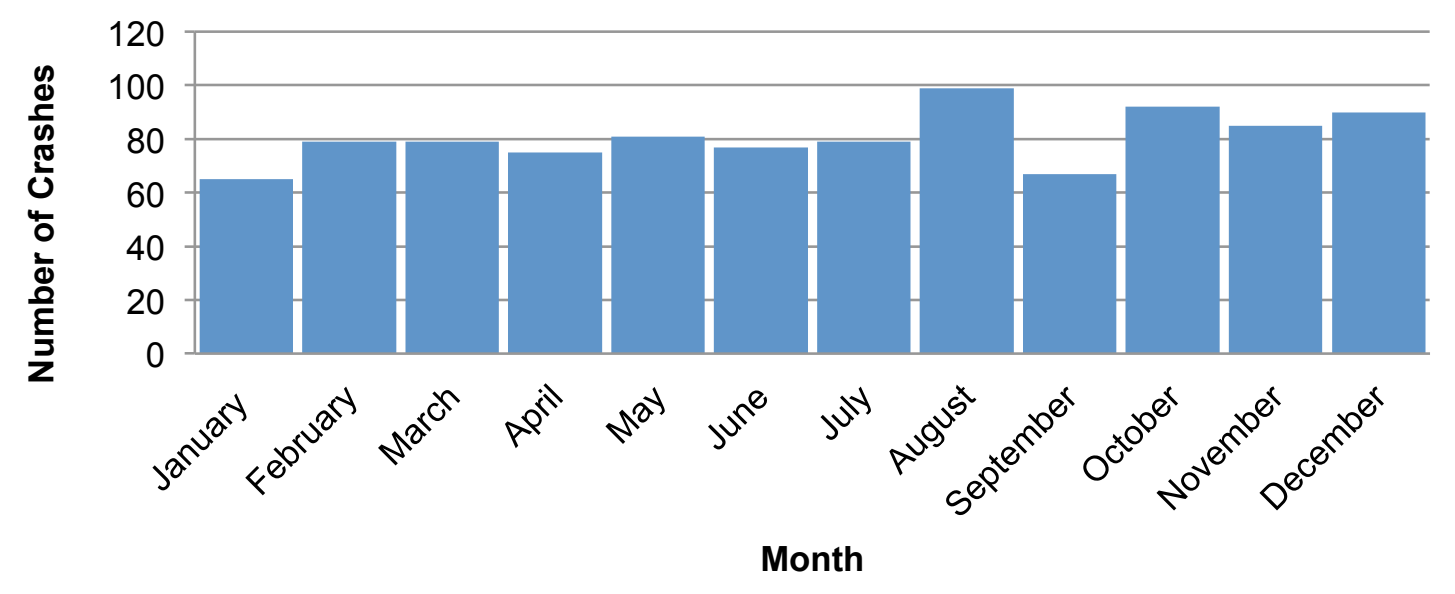

Data source: Traffic Injury Mapping System (TIMS), Safe Transportation

Research and Education Center (SafeTREC), University of California, Berkeley. 2013.

\subsubsection{Hourly}

Hourly crash distribution can help to discern patterns pertaining to sun glare and illumination. The distribution of crash proportions by age cohorts in Figure 8 shows that older drivers are more likely to crash during daylight hours than younger drivers. Twenty percent of all the crashes that occurred among drivers over 60 years of age are occurred in the 11:00 AM and 4:00 PM hours. Roughly $11 \%$ of crashes that occurred among drivers under 25 year occurred at the 2:00 AM hour. Even though older drivers appear to have a lower crash incidence during night hours, this trend may be due to exposure because senior drivers will generally drive less at nighttime. 
Jurado-Pina et al (2010) found that sun-glare, particularly evening glare, poses a risk at the exit of tunnels and concluded that crash occurrences are strongly influenced by sunlight glare. The expectation would be that a significant amount of collisions would have occurred during glare times, at the exit of tunnels rather than entrances, and if they were true, older drivers would have a higher crash rate frequency under this condition. In California, evening sun glare occurs between 3:00 PM and 6:00 PM. This trend is supported by the hourly distribution of crash proportions among older drivers in Figure 8 which shows that a large proportion of crashes among older drivers occur between 4:00 PM and 7:00 PM. Furthermore, Figure 7 shows that $77 \%$ of crashes involving older drivers occur during daylight and 17 percent under dark conditions (including street lights and no street lights). This trend should not be interpreted as older drivers having better nighttime vision; rather it shows that older drivers tend to drive less at nighttime. 
Figure 7. Crash Distribution by Lighting and Age Cohort (2002-2011)

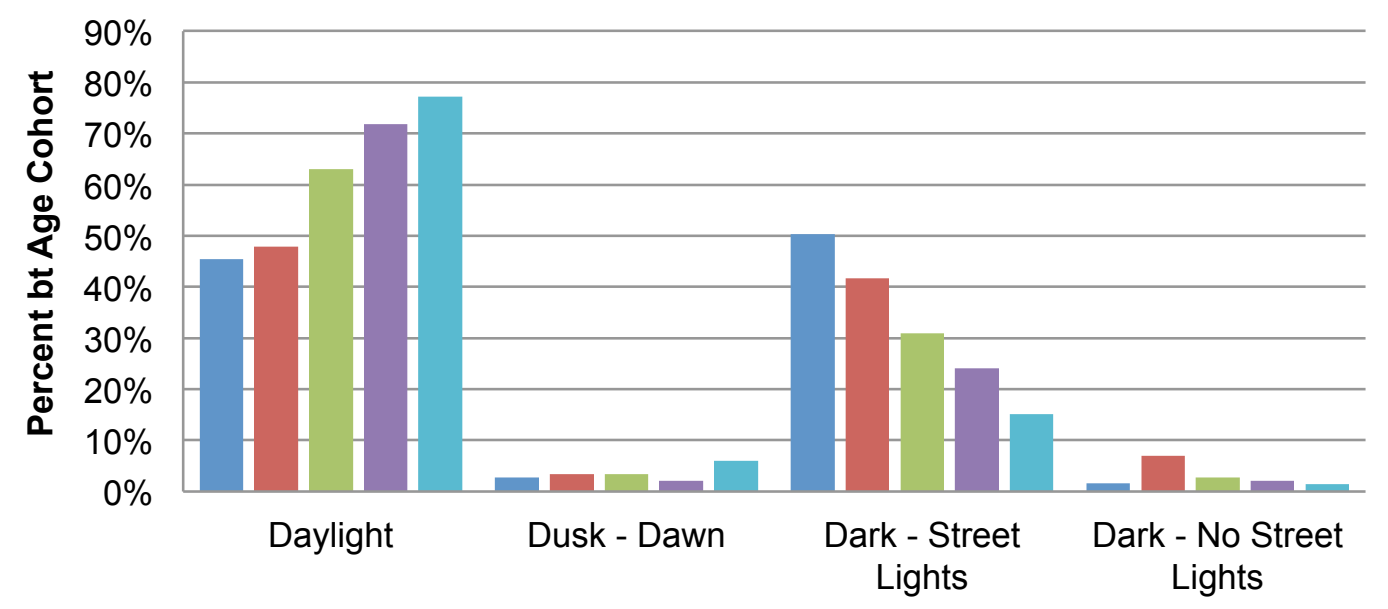

Lighting

Under 25 Yrs $\quad 26-29$ Yrs $\square$ 30-45 Yrs $\square$ 46-59 Yrs $\quad 0 v e r 60$ Yrs

Data source: Traffic Injury Mapping System (TIMS), Safe Transportation

Research and Education Center (SafeTREC), University of California, Berkeley. 2013. 
Figure 8. Hourly Crash Distribution by Age Cohort (2002-2011)

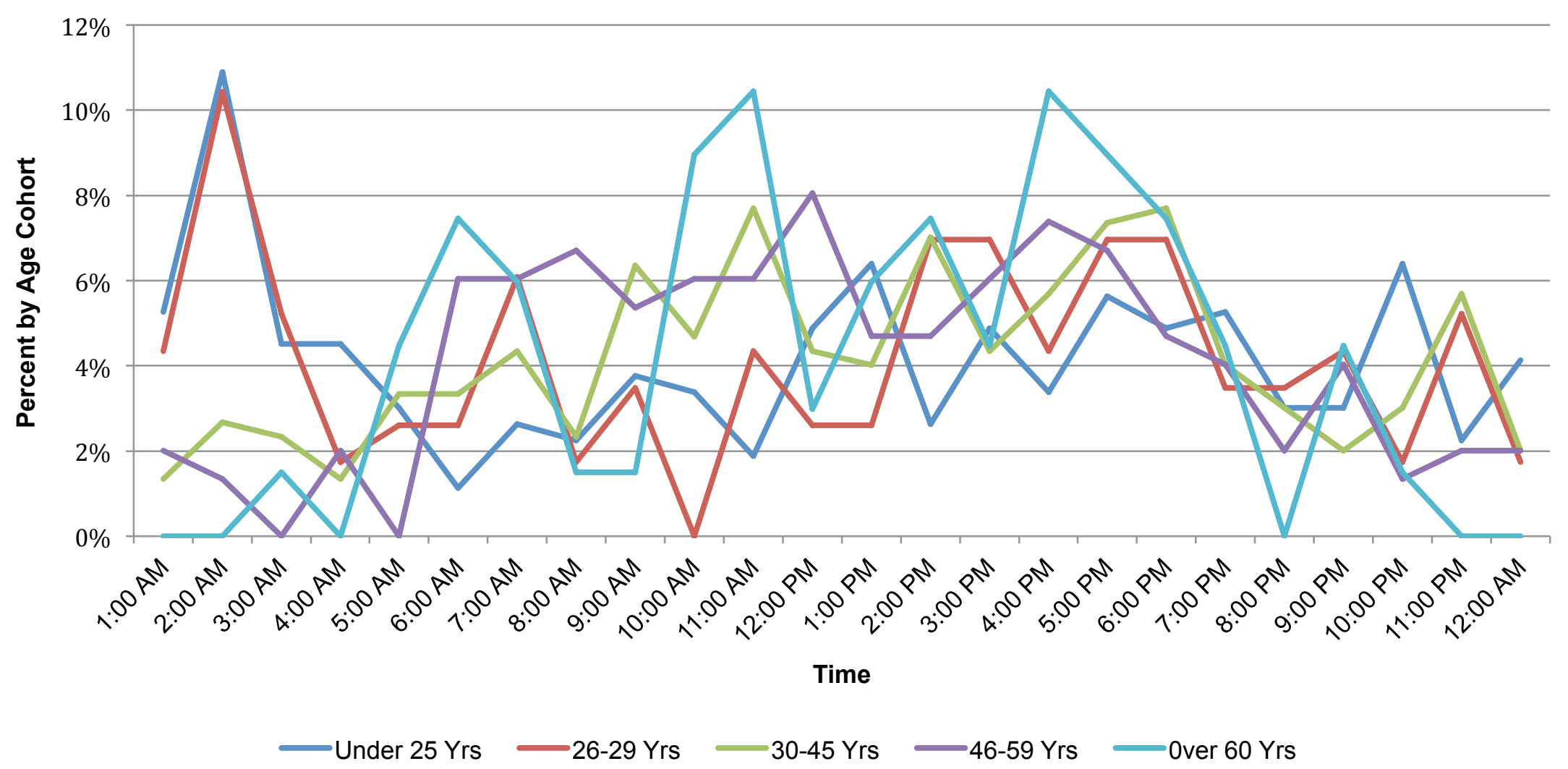

Data source: Traffic Injury Mapping System (TIMS), Safe Transportation Research and Education Center (SafeTREC), University of California, Berkeley. 2013. 


\subsubsection{Tunnel Location - Entrance, In Tunnel and Exit}

Ma et al (2009) reported that accident rates were highest at the entrance zones of tunnels and the highest severity occurred inside the tunnel rather than in the open road. Based on the hypothesis that older drivers are at a higher risk of crashing under drastic lighting changes, it is expected that the majority of crashes would occur inside the tunnel as drivers encounter the first drastic change in lighting entering the tunnel and a second change as they exit. Figure 9 shows the proportion of accidents that occurred at the entrance, tunnel and exit for each. More than $50 \%$ of all crashes of drivers 60 years and older occurred inside the tunnel, $34 \%$ at the entrance and $14 \%$ at the exit.

A chi-square test was performed to test whether location of crash and age were independent of each other. At an alpha level of $5 \%$, a X $X^{2}$ value of 15 , and eight degrees of freedom, there is a $5.8 \%$ probability that this distribution had occurred by chance. At an alpha level of $5 \%$, the null hypothesis stating that crash location is independent from driver's age is accepted. Table 4 shows the frequency table of observed vs. expected results of each age cohort at each location. 
Figure 9. Crash Distribution by Tunnel Location and Age Cohort (2002-2011)

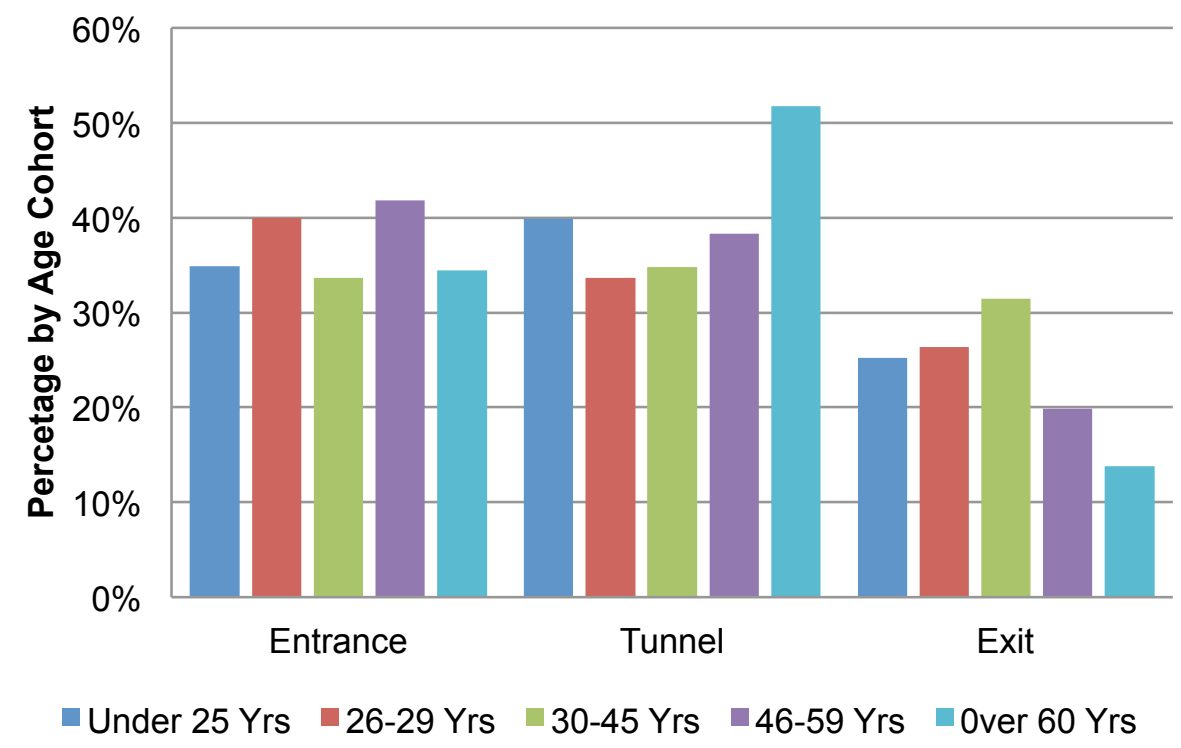

Data source: Traffic Injury Mapping System (TIMS), Safe Transportation Research and Education Center (SafeTREC), University of California, Berkeley. 2013. 
Table 4. Tunnel Location: Chi-Square Frequency (2002-2011)

\begin{tabular}{|l|c|c|c|c|c|c|c|c|c|c|c|}
\hline \multirow{2}{*}{ Location } & \multicolumn{2}{|c|}{ Under 25 Yrs } & \multicolumn{2}{c|}{$26-29$ Yrs } & \multicolumn{2}{c|}{$30-45$ Yrs } & \multicolumn{2}{c|}{$46-59$ Yrs } & \multicolumn{2}{c|}{ 0ver 60 Yrs } & \multirow{2}{*}{ Total } \\
\cline { 2 - 12 } & Observed & Expected & Observed & Expected & Observed & Expected & Observed & Expected & Observed & Expected & \\
\hline Entrance & 83 & 86 & 44 & 40 & 92 & 99 & 59 & 51 & 20 & 21 & 298 \\
\hline Tunnel & 95 & 90 & 37 & 42 & 95 & 104 & 54 & 53 & 30 & 22 & 311 \\
\hline Exit & 60 & 61 & 29 & 28 & 86 & 70 & 28 & 36 & 8 & 15 & 211 \\
\hline Total & 238 & & 110 & & 273 & & 141 & & 58 & 820 \\
\hline
\end{tabular}

Chi-Square value

Degrees of Freedom

P-Value (right tail)
15

0.059

Data source: Traffic Injury Mapping System (TIMS), Safe Transportation Research and Education Center (SafeTREC),

University of California, Berkeley. 2013. 
The second most common crash location among all drivers is prior to entering the tunnel and as vehicles proceed to enter. A plausible explanation for this phenomenon is the shockwave effect triggered by the tunnel condition on the upstream traffic. As discussed in the literature, different drivers react to tunnels differently and some will increase their speed to exit quickly, while others will slow down to proceed with greater caution. These differences in traffic flow have an influence on the upstream traffic, fostering the traffic conditions that will lead to rear-end crashes.

\subsubsection{Collision Type}

Figure 10 shows the distribution of crash types by age. Rear-end collisions are the most common type of crashes along highways, in every age group. On most freeways, traffic travels along divided group of lanes, which increases the likelihood of rear-end type collisions and reduces the likelihood of broadside and head-on collisions. Drivers have different reactions to tunnel conditions; some may exhibit indifference while others may experience driving impairment due to tenseness, fear or physical conditions such as vision. The non-uniformity of driver response may be associated with rear-end type collisions. While some drivers reduce their speed, others increase their velocity to quickly exit the tunnel. 
Figure 10. Crash Distribution by Crash Type and Age Cohort (2002-2011)

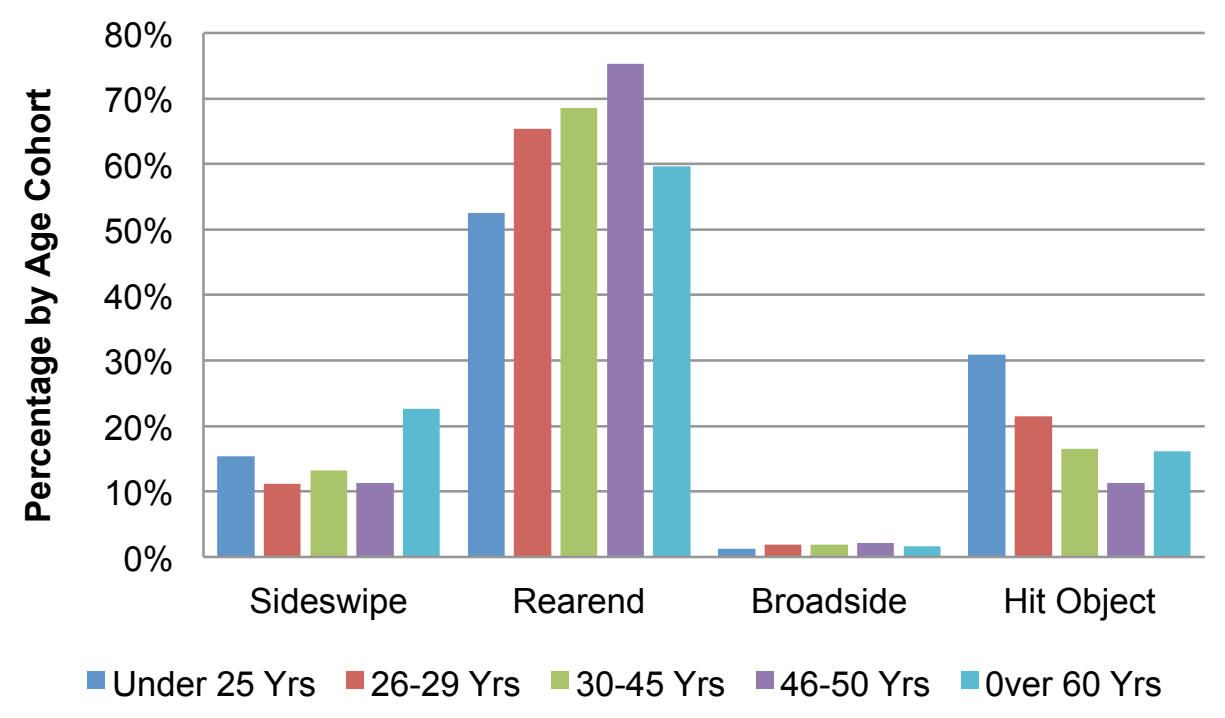

Data source: Traffic Injury Mapping System (TIMS), Safe Transportation Research and Education Center (SafeTREC), University of California, Berkeley. 2013. 


\subsubsection{Driver and Party Characteristics}

\subsubsection{Sex}

Zhao et al (2009) claim that in tunnels, males drive at a higher speed and have a lower heart rate increase than females. Heart rate increase is indicative of tenseness leading to erratic driving behavior such as sudden breaking, which may result in rear-end collisions. Based on this assumption, we would expect a higher number of crashes involving women, considering an almost even distribution of the total population, between male and female as show Figure 11 However, male drivers at every age cohort had a higher crash percentage than female drivers. Males accounted for more than $60 \%$ of all recorded crashes in every age cohort as indicated in Turner and McClure (2003) state "risk-taking behavior has been identified as a possible explanation for the high incidence of motor vehicle crashes involving young male drivers", this trend is also applicable to older males because this study also found that males are twice more likely to be involved in a crash. 
Figure 11. Crash Distribution by Sex and Age Cohort (2002-2011)

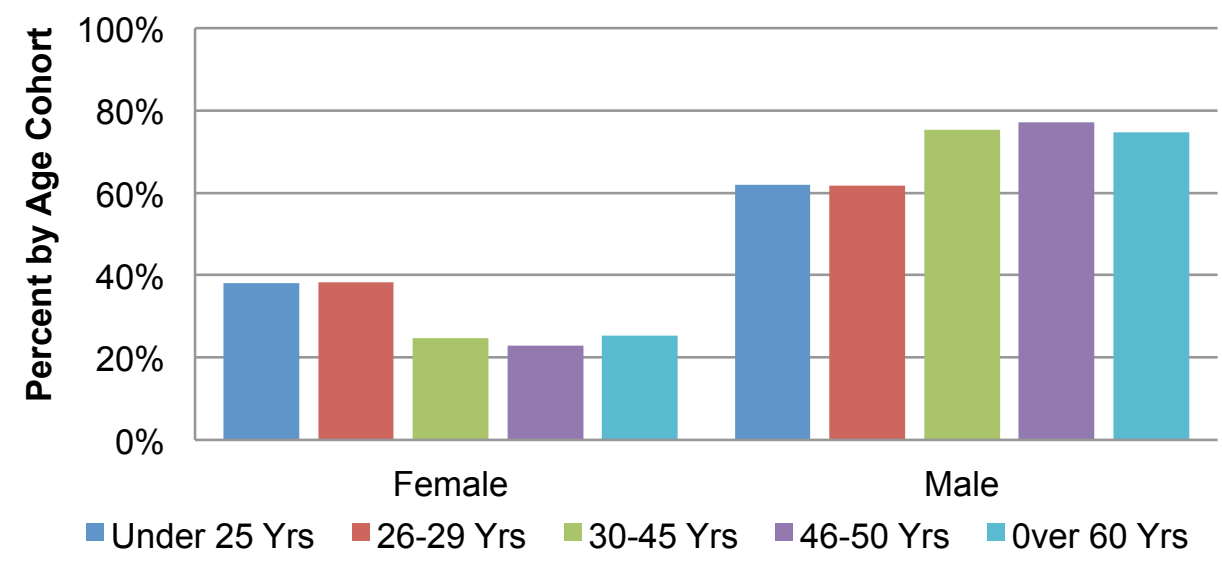

Data source: Traffic Injury Mapping System (TIMS), Safe Transportation Research and Education Center (SafeTREC), University of California, Berkeley. 2013dsfsfs

\subsubsection{Old Drivers vs. Young Drivers}

As the proportion of older drivers increases and if older drivers are more susceptible to high glare conditions, then it would be expected to have a high frequency of collisions under tunnel conditions. However, data in injury collisions suggests that older drivers are not the most likely to collide in tunnels, but rather young drivers, Table 5 shows the distribution of proportion of drivers at fault of a crash and their proportion of the total population. 
Table 5. Age Distribution of Percent Involve in Crash and Age Percentage

\begin{tabular}{r|c|c|} 
Age & $\begin{array}{c}\text { Percent of } \\
\text { Population }\end{array}$ & $\begin{array}{c}\text { Percent } \\
\text { Involved in } \\
\text { Crashes }\end{array}$ \\
\hline 15 to 19 & $6 \%$ & $5 \%$ \\
\hline 20 to 29 & $19 \%$ & $28 \%$ \\
\hline 30 to 39 & $19 \%$ & $27 \%$ \\
\hline 40 to 49 & $19 \%$ & $19 \%$ \\
\hline 50 to 59 & $16 \%$ & $13 \%$ \\
\hline 60 to 69 & $10 \%$ & $5 \%$ \\
\hline 70 to 79 & $6 \%$ & $2 \%$ \\
\hline 80 and over & $4 \%$ & $1 \%$ \\
\hline
\end{tabular}

Data source: QT-P1-Geography-California: Age Groups and Sex: 2010

Summary File 1, Tables P12, P13, and PCT12.

2010 Census Summary File 1

The inequality in population and crash proportions is illustrated using a Lorenz Curve in Figure 12. The diagonal line indicates perfect equality among proportions, and the curve line indicates actual conditions. Equality is a measure of how close or apart the line of actual conditions is from the diagonal line. A case of perfect equality will mean that crash proportions among age cohorts is perfectly proportional to the proportion that they account for in the total population, if drivers ages $60-69$ account for $10 \%$ of the population, then this 
group will also account for $10 \%$ of all crashes. The Lorenz Curve in Figure 12 shows that there is great inequality between population and crash proportions.

The Gini Coefficient is a quantifiable indicator of inequality that measures the ratio of areas on the Lorenz Curve. This value ranges from zero to one, where zero represents perfect equality a value of one represents perfect inequality. The Gini Coefficient for this sample data is, 0.26 in the Gini Index (See Appendix D for calculations).

Figure 12. Lorenz Curve: Crashes vs. Population

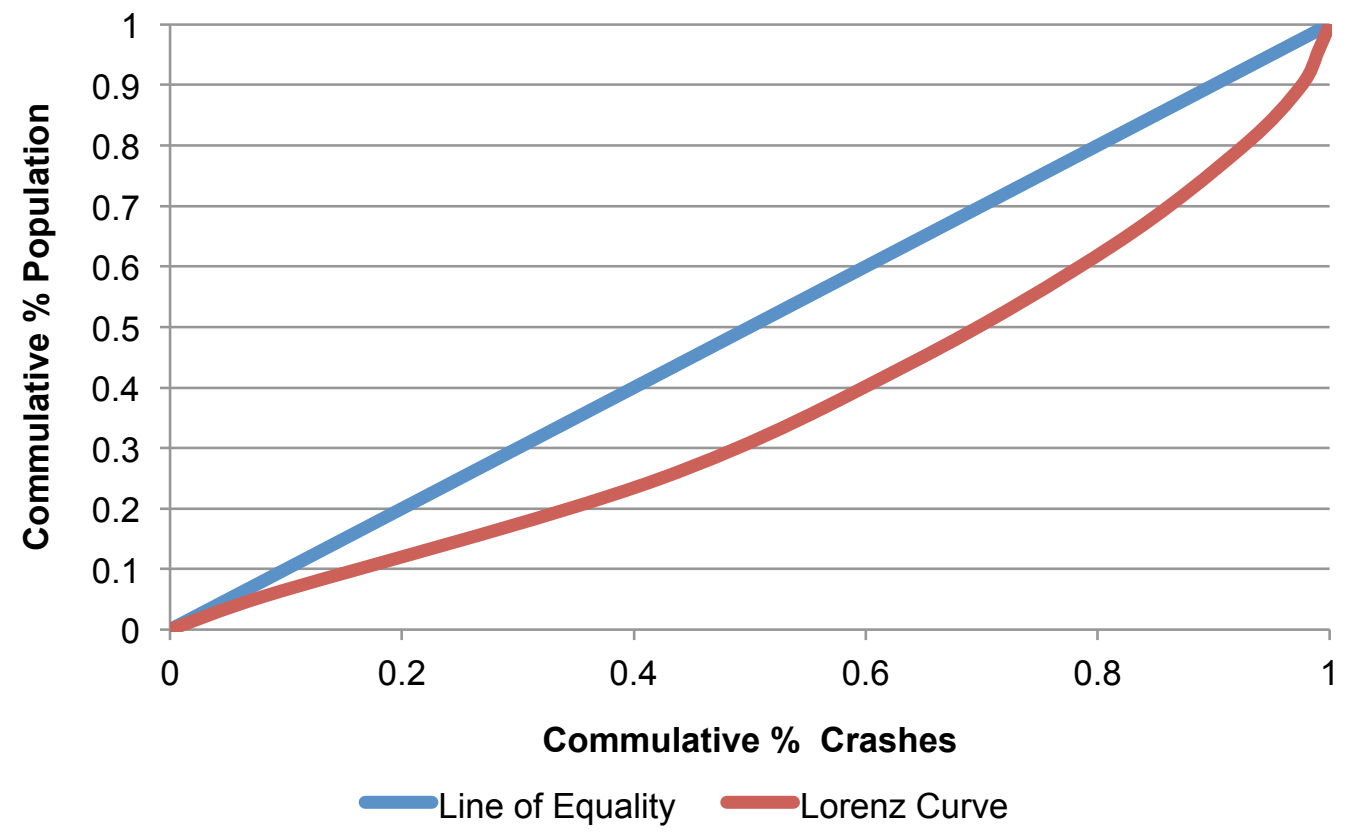

Data source: QT-P1-Geography-California: Age Groups and Sex: 2010

Summary File 1, Tables P12, P13, and PCT12.

2010 Census Summary File 1 
The Lorenz Curve and Gini coefficient shows that there is great inequality in the distribution of crashes as compared to population proportion, but it does not indicate a direction in which this inequality exits or the degree to which one age group is under or over represented. However, Table 6 shows that younger drivers are overly represented in the injury crashes associated with tunnels.

Discrepancies between the literature and actual collisions could be explained by self-restriction behavior within the older population. Sullivan et al (2010) argued that driving can become a difficult task for older drivers as their vision and mobility abilities begin to deteriorate so that elderly drivers may opt to abstain from driving. Thus, collision exposure in older drivers would be reduced if older drivers were restricting themselves from driving.

The low incidence of crashes in tunnels among older drivers may be associated with DMV's vision test program that puts limitations on drivers with sight deterioration or does not grant them a driver's license at all.

\subsubsection{Involvement}

Who was involved in the accident? Are older people more likely to be involved on accidents at the exit/entrances of tunnels? Even when older drivers are denoted as not at fault of a crash, drivers with physical impairments are less likely to react in a timely manner and prevent a crash, thus increasing involvement. Mckelvey et al (1988) question whether "accident involvement as an innocent victim increases in direct proportion to accident exposure." The cause for this may be attributed to a misjudgment of who was at fault or fragility. TIMS 
only reports fatal or injury collisions, and collisions among older drivers are more likely to result in an injury or fatality, thus older drivers would be more likely to be involved in an injury or fatal crash. However, Figure 13 shows that young people are more likely to be involved in an accident, than older people. For example, people ages 20 to 29 years old account for $19 \%$ of the population, and for $28 \%$ of the parties involve in an injury or fatal accident as either a driver or passenger.

Figure 13. Age Distribution of Parties Involved in a Crash

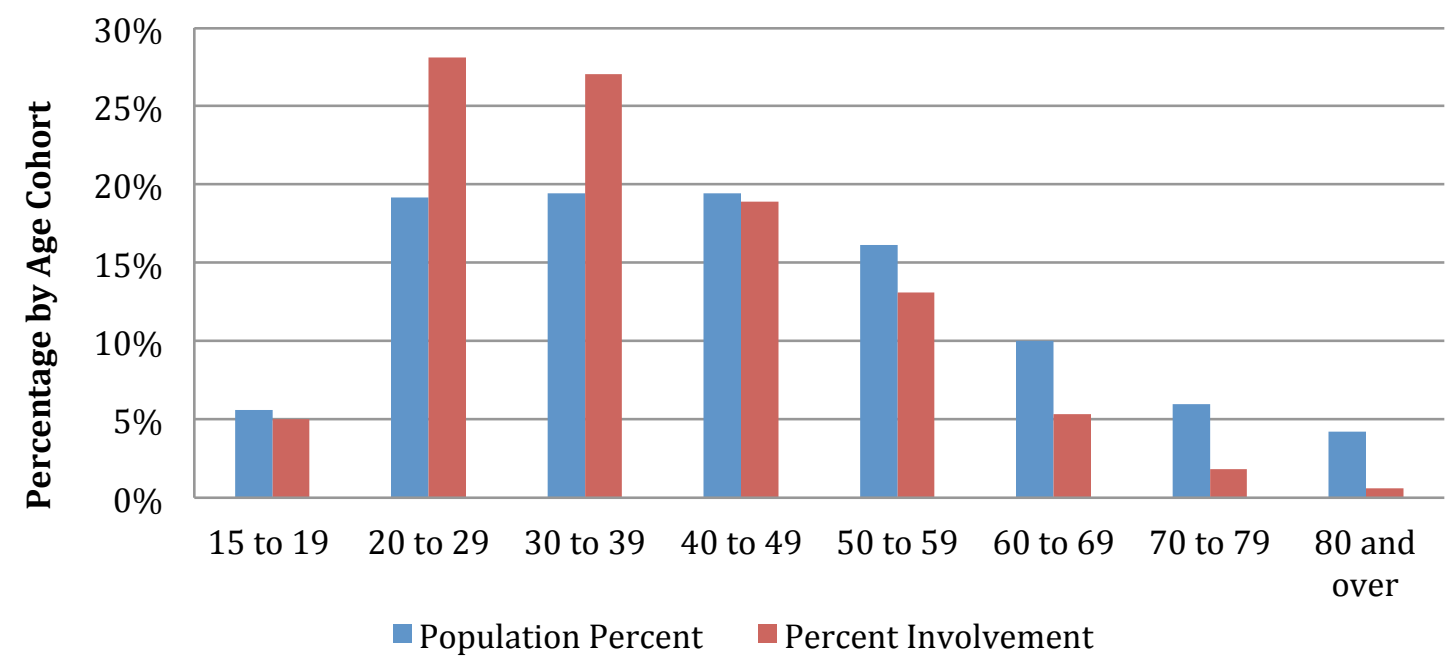

Data source: Traffic Injury Mapping System (TIMS), Safe Transportation Research and Education Center (SafeTREC), University of California, Berkeley.

QT-P1-Geography-California: Age Groups and Sex: 2010

Summary File 1, Tables P12, P13, and PCT12.

2010 Census Summary File 1 
Figure 14 shows the severity of crashes by age group. A chi-square test was performed to test whether crash severity and age were independent of each other. At an alpha level of $5 \%$, a $X^{2}$ value of 26 , and 12 degrees of freedom, there is a $1 \%$ probability that this distribution had occurred by chance. There is an association between age and crash severity. Table 6 shows the crash severity distribution of observed and expected crashes among each age cohort, which shows that the expected frequency among drivers aged 25 and under being involve in a fatal collision was four, but no cases were observed. This suggests that younger drivers may be less likely to be involved in severe crashes.

Figure 14. Age Distribution of Crash Severity (2002-2011)

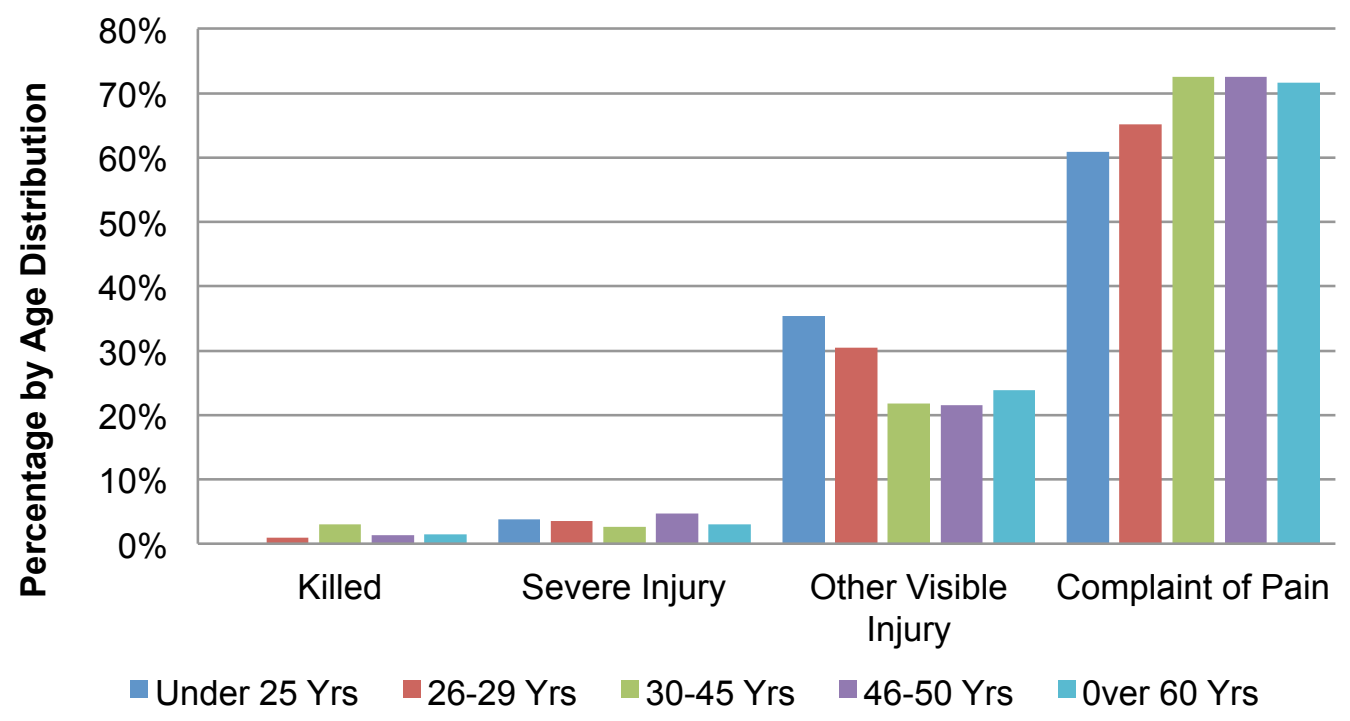

Data source: Traffic Injury Mapping System (TIMS), Safe Transportation Research and Education Center (SafeTREC), University of California, Berkeley. 
Table 6. Crash Severity - Chi-Square Frequency (2002-2011)

\begin{tabular}{|c|c|c|c|c|c|c|c|c|c|c|c|}
\hline \multirow{2}{*}{ Sobriety } & \multicolumn{2}{|c|}{ Under 25 Yrs } & \multicolumn{2}{|c|}{$26-29$ Yrs } & \multicolumn{2}{|c|}{$30-45$ Yrs } & \multicolumn{2}{|c|}{$46-59$ Yrs } & \multicolumn{2}{|c|}{ 0ver 60 Yrs } & \multirow{2}{*}{ Total } \\
\hline & Observed & Expected & Observed & Expected & Observed & Expected & Observed & Expected & Observed & Expected & \\
\hline Killed & 0 & 4 & 1 & 2 & 9 & 4 & 2 & 2 & 1 & 1 & 13 \\
\hline $\begin{array}{l}\text { Severe } \\
\text { Injury }\end{array}$ & 10 & 9 & 4 & 4 & 8 & 10 & 7 & 5 & 2 & 2 & 31 \\
\hline $\begin{array}{l}\text { Other } \\
\text { Visible } \\
\text { Injury }\end{array}$ & 94 & 72 & 35 & 31 & 65 & 81 & 32 & 40 & 16 & 18 & 242 \\
\hline $\begin{array}{l}\text { Complaint } \\
\text { of Pain }\end{array}$ & 162 & 181 & 75 & 78 & 217 & 204 & 108 & 101 & 48 & 46 & 610 \\
\hline Total & 266 & & 115 & & 299 & & 149 & & 67 & & 896 \\
\hline
\end{tabular}

Chi-Square Value = 26; Degrees of Freedom $=12 ; \mathrm{P}$-Value $($ right tail $)=0.0107$

Data source: Traffic Injury Mapping System (TIMS), Safe Transportation Research and Education Center (SafeTREC),

University of California, Berkeley. 


\subsubsection{Violation Category}

Violation category is an indicator of what is triggering crashes. Unsafe speed is the dominant reason and accounts for more than $44 \%-54 \%$ of all crashes among all age groups as shown in Figure 15. It is important to note that drivers age 60 years and older have the lowest proportion of unsafe speed violations. Unsafe lane change accounts for $24 \%$ of all crashes that occur among drivers age 60 and older and appears to be the category where seniors perform relatively worse than others. As explained in the literature review, sight deterioration affects a driver's ability to detect peripheral information. Peripheral information is very important to determine whether it is safe to change lanes or not, and based on this observation, older drivers appear to have trouble changing lanes safely.

Figure 15. Crash Distribution by Age and Violation Category (2002-2011)

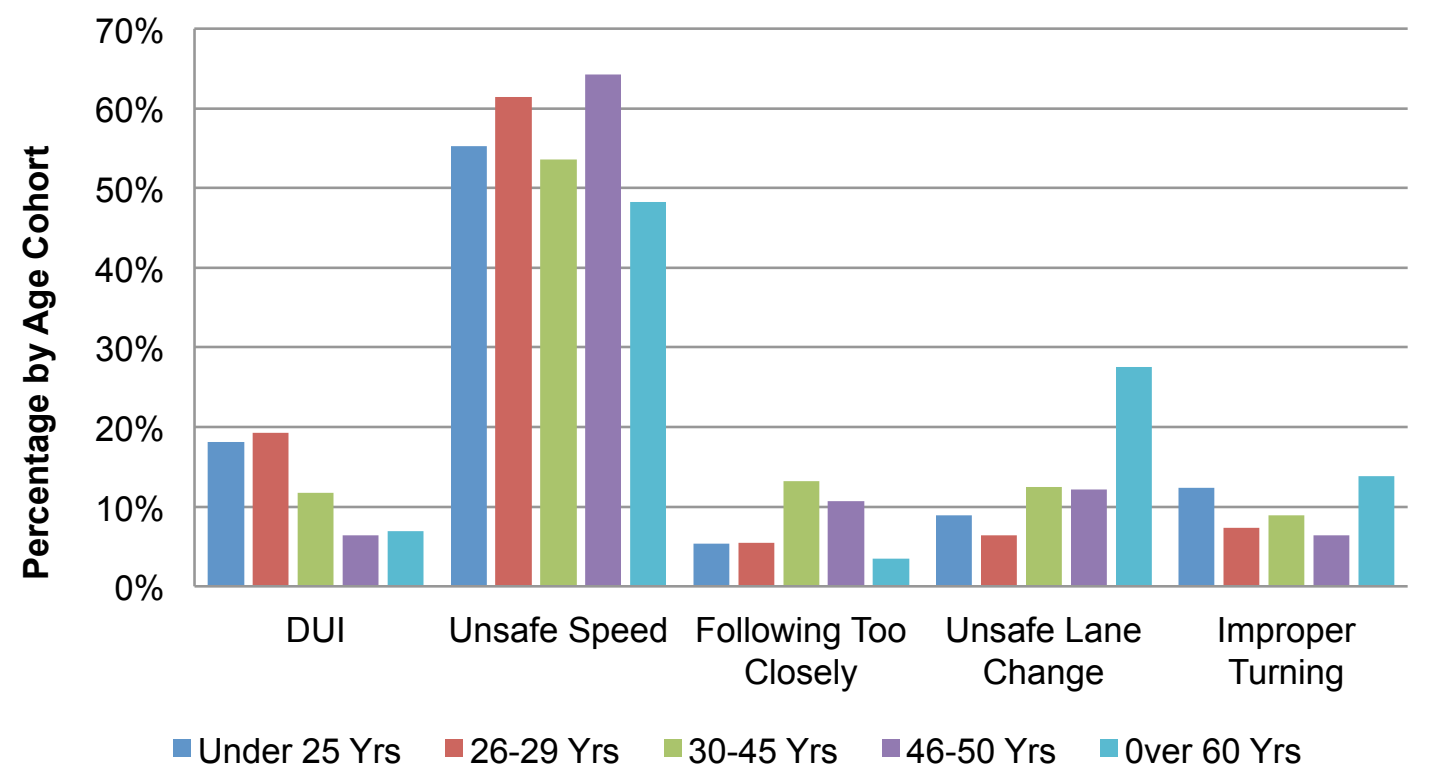


Data source: Traffic Injury Mapping System (TIMS), Safe Transportation

Research and Education Center (SafeTREC), University of California, Berkeley.

\subsubsection{Sobriety}

There have been a wide number of studies that investigate the effects of alcohol on driving performance. It has been generally accepted that driving under the influence of alcohol negatively affects a driver's reaction time and ability to drive; furthermore drivers are more likely to engage in high-risk behavior (Cohen et al, 1958).

A chi-square test of independence was performed to determine if there is a statistically significant relationship between age and whether a person crashes while driving under the influence. At an alpha level of $5 \%$, a $X^{2}$ value of 21 , and eight degrees of freedom, there is a $0.7 \%$ probability that this distribution had occurred by chance. Table 7 shows the crash frequency distribution of observed and expected crashes among each age cohort, which shows that the expected frequency of drivers' age 60 year and older is expected to be eight, but only four crashes were observed. On the other hand, younger drivers have a higher number of observed crashes then expected, 42 and 32 respectively. Concluding that there is an association between age and DUI's. As seen by a general observation in Figure 16, older drivers have a lower percentage of DUI involvement. 
Figure 16. Crash Distribution by Driver Sobriety and Age

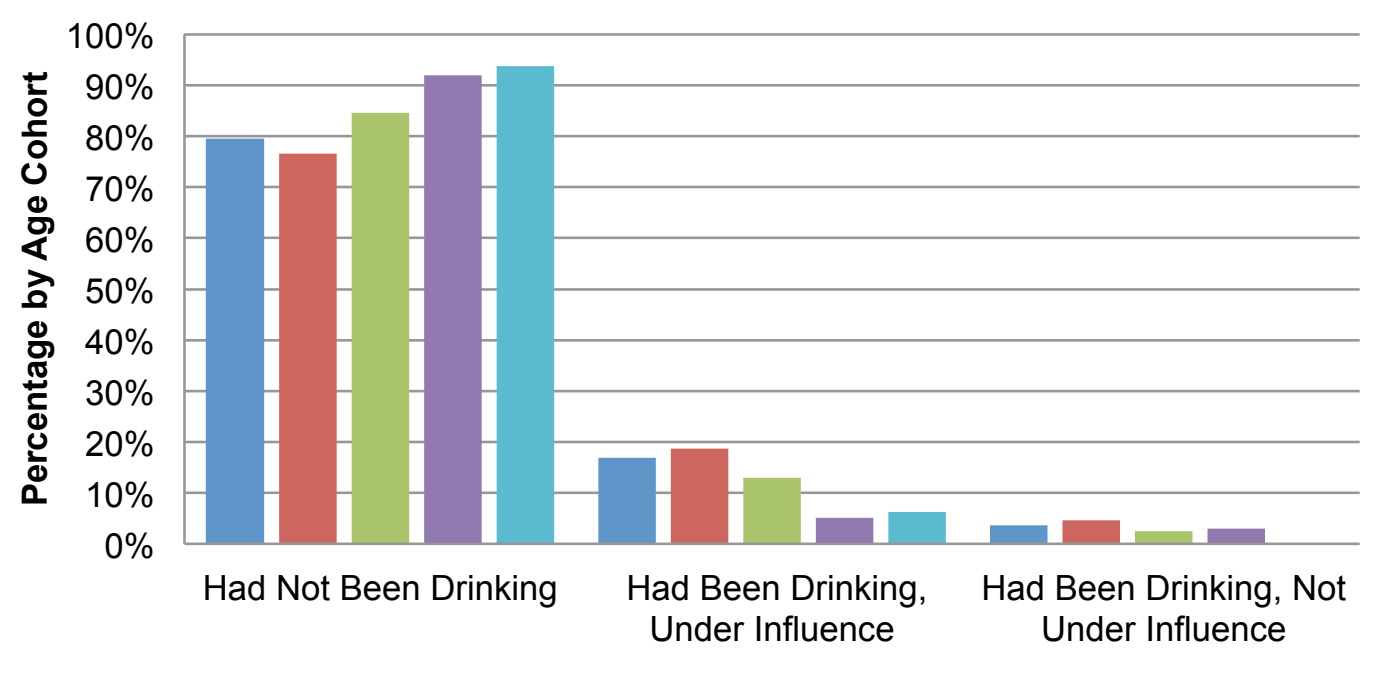

- Under 25 Yrs $\quad 26-29$ Yrs $\quad 30-45$ Yrs $\quad 46-59$ Yrs $\quad 0$ ver 60 Yrs

Data source: Traffic Injury Mapping System (TIMS), Safe Transportation

Research and Education Center (SafeTREC), University of California, Berkeley. 
Table 7: Sobriety - Chi-square Frequency (2002-2011)

\begin{tabular}{|c|c|c|c|c|c|c|c|c|c|c|c|}
\hline \multirow{2}{*}{ Sobriety } & \multicolumn{2}{|c|}{ Under 25 Yrs } & \multicolumn{2}{|c|}{$26-29$ Yrs } & \multicolumn{2}{|c|}{$30-45$ Yrs } & \multicolumn{2}{|c|}{$46-59$ Yrs } & \multicolumn{2}{|c|}{ Over 60 Yrs } & \multirow{2}{*}{ Total } \\
\hline & Observed & Expected & Observed & Expected & Observed & Expected & Observed & Expected & Observed & Expected & \\
\hline $\begin{array}{l}\text { Had Not } \\
\text { Been } \\
\text { Drinking }\end{array}$ & 198 & 209 & 82 & 90 & 243 & 241 & 125 & 114 & 60 & 54 & 708 \\
\hline $\begin{array}{l}\text { Had Been } \\
\text { Drinking, } \\
\text { Under } \\
\text { Influence }\end{array}$ & 42 & 32 & 20 & 14 & 37 & 37 & 7 & 18 & 4 & 8 & 110 \\
\hline $\begin{array}{l}\text { Had Been } \\
\text { Drinking, } \\
\text { Not Under } \\
\text { Influence }\end{array}$ & 9 & 7 & 5 & 3 & 7 & 9 & 4 & 4 & 0 & 2 & 25 \\
\hline Total & 249 & & 107 & & 287 & & 136 & & 64 & & 843 \\
\hline \multicolumn{12}{|c|}{ Chi-Square value $\quad 21$} \\
\hline \multicolumn{2}{|c|}{ Degrees of Freedom } & $\begin{array}{r}8 \\
0.007\end{array}$ & & & & & & & & & \\
\hline
\end{tabular}

Data source: Traffic Injury Mapping System (TIMS), Safe Transportation Research and Education Center (SafeTREC),

University of California, Berkeley. 


\section{CONCLUSION AND RECOMMENDATIONS}

\subsection{Concluding Observations}

Contrary to what was expected based on the literature review, younger, not older drivers, are more at risk of being involved in a tunnel collision. This study has found that drivers over 60 years and older are proportionately under distributed in the crash data despite their inability to quickly adapt in the changing lighting environment of tunnels. Drivers under the age of 25 have higher proportions of fatal and injury crashes at tunnel locations that may be associated with high-risk behavior. The data showed that a higher proportion of young drivers were involved in DUI crashes and in crashes where unsafe speed was the primary collision violation.

The literature suggests that older people are more likely to collide in tunnels due to cognitive and physical impairments. However, all studies found in the literature were performed in a controlled environment that quantified performance based on physical and cognitive ability. Furthermore, these studies also pre-determined exposure by including a fix proportion of subjects from every age category. Controlled experiments do not account for exposure, erratic behavior and Driving Under the Influence conditions. Even though the vision of young drivers adapts faster to changes in lighting than that of older drivers, there are other factors that can be more crash inducing than sight deficiencies. 
The under representation of the senior drivers in the crash data may also be explained by voluntary driving retirement and driver license restrictions. It may be possible that senior drivers account for a lower proportion of crashes if a lower proportion of them drive. Older drivers are more likely to have more driving restrictions, so it is likely that many of them retire from driving, or drive shorter distances and make fewer trips. Stutts (1998) found that a "clear pattern of reduced driving exposure" is observed among older drivers with visual and cognitive impairments. Thus the low incidence of tunnel crashes among older drivers in this study can be explained if indeed older drivers are less exposed to crashing because they drive less.

\subsection{Recommendations}

Even though this study suggests that older drivers are under represented in crash collisions at the entrances and exits of tunnels, in comparison to younger drivers, this does not eliminate the existing problem. Even if there are only a small proportion of older drivers due to vision impairments, actions that mitigate older drivers' potential hazard to crash should be taken. The State of California has addressed the issue of vision impairment in drivers by administering a vision test as part of issuing a driver's license and before renewal for drivers with existing restrictions. The underrepresentation of senior crashes due to vision impairments may be attributed to the established DMV vision test requirement, but additional steps can be taken to further safety among older drivers. A way to improve this program would be to increase the frequency of vision checks for 
senior drivers to verify the adequacy of their existing prescription and verify their vision performance.

Another recommendation is to encourage the voluntary driving retirement among senior drivers with vision and physical impairments by providing alternative means of transportation that would allow them to maintain mobility and access that meets their needs. Not being able to drive would put a barrier in a person's mobility, thus it is important that elderly people have options of mobility access for when they are no longer able to drive. Improving and expanding public transportation services can allow older drivers to give up their driving privileges and still be able to meet their transportation needs.

According to this study, the population that is more at risk of being involved in an injury or fatal collision includes drivers 25 and under, this trend has not been linked to a single set of factors, but is rather associated with a complex set of factors that include high-risk behavior and inexperience. Based on these observations, it is recommended that efforts be made to educate drivers of ages 25 years and under about the serious risk of reckless driving and speeding. An alternative would be to impose stricter penalties for citations that involve high-risk driving behavior that border on reckless driving.

A general recommendation is for the jurisdiction responsible for the maintenance of each tunnel to take preventative action by making periodic safety audits to test brightness, dimness, glare, ventilation, surface conditions and 
overall performance. The agency can subsequently mitigate conditions to prevent future crashes.

\subsection{Further Investigation}

Road tunnels are constantly being renovated with new technological improvements in lighting, ventilation and overall safety. In 2001 a press release by Caltrans announced that new lighting was going to be installed in the Caldecott Tunnel, along Highway 24. The purpose of this renovation was to install brighter energy efficient lighting as part of a project aiming to conserve energy. However, it would also be important to assess what impact the new lighting has had on traffic safety.

A major renovation in a tunnel would provide the basis to perform a comparative study that would evaluate the performances of installing new lighting. Collision information from before and after the renovation can be use to determine whether there was a decrease in crash rate or if there was a difference in the age distribution in parties involved. If an improvement in traffic safety is noted after the evaluation, then the data could become a point of reference and be use to improve tunnels with similar characteristics. 


\section{BIBLIOGRAPHY}

Amado, S., Arıkan, E., Kaça, G., Koyuncu, M., \& Turkan, B. N. (2014). How accurately do drivers evaluate their own driving behavior? An on-road observational study. Accident Analysis \& Prevention, 63, 65-73.

Arends, B. J., Jonkman, S. N., Vrijling, J. K., \& van Gelder, P. (2005). Evaluation of tunnel safety: towards an economic safety optimum. Reliability Engineering \& System Safety, 90(2), 217-228.

Auffray, B., Monsere, C. M., and Bertini, R. L. (2008). "An empirical investigation of the impacts of sun-related glare on traffic flow." Proc., $87^{\text {th }}$ Annual Meeting of Transportation Research Board (CD-ROM), Transportation Research Board, Washington, D.C.

Ball, K., Beard, B., Roenker D., Miller, R., Griggs, D., 1988. Age and visual search: expanding the useful field of view. Journal of the Optical society of America 5(12), 2210-2219.

Bailey, I. L., \& Sheedy, J. E. (1988). Vision screening for driver licensure. Transportation in an Aging Society, 2, 294-324.

Bayam, E., Liebowitz, J., \& Agresti, W. (2005). Older drivers and accidents: A meta analysis and data mining application on traffic accident data. Expert Systems with Applications, 29(3), 598-629.

Beard, A. N. (2010). Tunnel safety, risk assessment and decision-making. Tunneling and Underground Space Technology, 25(1), 91-94. 
Carr, D., Jackson, T. W., Madden, D. J., \& Cohen, H. J. (1992). The effect of age on driving skills. Journal of the American Geriatrics Society, 40(6), 567.

Charman, W. N. (1997). Vision and driving—a literature review and commentary. Ophthalmic and Physiological Optics, 17(5), 371-391.

Cohen, J., Dearnaley, E. J., \& Hansel, C. E. M. (1958). The risk taken in driving under the influence of alcohol. British Medical Journal, 1(5085), 1438.

DeGroat, B. (2009). Autumn driving is the most hazardous fatality crash rates peak in the fall of the year, with October topping out at 10.2 deaths per billion kilometers. SperoNews. Retrieved from http://www.speroforum.com/a/19872/Autumn-driving-is-the-mosthazardous

DeRamus, R., \& Fisher, D. L. (2004). The effect of driver age and experience on risk assessment and risk prediction. In Proceedings of the Human Factors and Ergonomics Society Annual Meeting (Vol. 48, pp. 2627-2631).

Retrieved from

http://pro.sagepub.com.ezproxy.lib.calpoly.edu/content/48/23/2627.short

Du, Z., Huang, F., \& Pan, X. (2013). Analysis on Fixation Distribution Characteristics of Drivers in Long Freeway Tunnels. In ICTIS 2013 (pp. 1251-1261). American Society of Civil Engineers. 
Du, Z., Pan, X., Yang, Z., \& Guo, X. (2007). Research on Visual Turbulence and Driving Safety of Freeway Tunnel Entrance and Exit [J]. China Journal of Highway and Transport, 5, 019.

Du, Z., Pan, X., \& Guo, X. (2008). "Evaluation Index's Application Studies on Driving Safety at Highway Tunnel's Entrance and Exit." Journal of Tongji University. Vol. 36, No.3, pp. 325-329.

Evans, G. W., Skorpanich, M. A., Garling, T., Bryant, K. J., \& Bresolin, B. (1984). The effects of pathway configuration, landmarks and stress on environmental cognition. Journal of Environmental Psychology, 4, 323335.

Gray, R., and Regan, D. (2007). "Glare susceptibility test results correlate with temporal safety margin when executing turns across approaching vehicles in simulated low-sun conditions." Ophthalmic Physiol. Opt., 27 (5), 440450.

Griffin, L. (2004). Older driver involvement in injury crashes in Texas 975-1999. AAA Foundation of Traffic Safety. Retrieved from http://newsroom.aaa.com/wpcontent/uploads/2011/09/OlderDriverInvolvementInInjuryCrashes.pdf

Groenhaug, A. (1997) Road tunnel linings: design for safety, comfort and aesthetics. Nordic Road \& Transport Research, 9, 4-6. 
Guirao, A., Gonzalez, C., Redondo, M., Geraghty, E., Norrby, S., \& Artal, P. (1999). Average optical performance of the human eye as a function of age in a normal population. Investigative Ophthalmology \& Visual Science, 40(1), 203-213.

Guirao, A., Redondo, M., \& Artal, P. (2000). Optical aberrations of the human cornea as a function of age. JOSA A, 17(10), 1697-1702.

Haigh, R. (1993). The ageing process: a challenge for design. Applied Ergonomics, 24(1), 9-14.

Harris, C. R., Jenkins, M., \& Glaser, D. (2006). Gender differences in risk assessment: Why do women take fewer risks than men. Judgment and Decision Making, 1(1), 48-63.

Hirakawa, S., Toeda, K., Sugawara, T., \& Sakamoto, S. (2012). Maintenance factor in installation of tunnel lighting. Journal of the Illuminating Engineering Institute of Japan (Shomei Gakkai Shi), 96(2), 69-74.

Holland, C. A., \& Rabbitt, P. (1992). People's awareness of their age-related sensory and cognitive deficits and the implications for road safety. Applied Cognitive Psychology, 6(3), 217-231.

Horberry, T., Anderson, J., Regan, M. A., Triggs, T. J., \& Brown, J. (2006). Driver distraction: the effects of concurrent in-vehicle tasks, road environment complexity and age on driving performance. Accident Analysis \& Prevention, 38(1), 185-191. 
Janke, M. K., \& Eberhard, J. W. (1998). Assessing medically impaired older drivers in a licensing agency setting. Accident Analysis \& Prevention, 30(3), 347-361.

Janoff, M. S. (1988). Effect of Bridge Lighting on Nighttime Traffic Safety. Retrieved from http://trid.trb.org/view.aspx?id=294393

Jurado-Piña, R., and Pardillo-Mayora, J., M. (2009). "A Methodology to predict driver vision impairment situations caused by sun glare." Transp. Transportation Research Board, Washington D.C., 12-17.

Jurado-Piña, R., Pardillo-Mayora, J., \& Jiménez, R. (2010). Methodology to Analyze Sun Glare Related Safety Problems at Highway Tunnel Exits. Journal of Transportation Engineering, 136(6), 545-553.

Kinateder, M., Pauli, P., Müller, M., Krieger, J., Heimbecher, F., Rönnau, I., Mühlberger, A. (2013). Human behaviour in severe tunnel accidents: Effects of information and behavioural training. Transportation Research Part F: Traffic Psychology and Behaviour, 17, 20-32.

Kircher, K., \& Ahlstrom, C. (2012). The impact of tunnel design and lighting on the performance of attentive and visually distracted drivers. Accident Analysis \& Prevention, 47, 153-161. doi:10.1016/j.aap.2012.01.019

Kircher, K., \& Lundkvist, S.-O. (2011). The Influence of Lighting, Wall Colour and Inattention on Traffic Safety in Tunnels: A Simulator Study. Retrieved from 
http://www.vti.se/en/publications/pdf/the-influence-of-lighting-wall-colourand-inattention-on-traffic-safety-in-tunnels--a-simulator-study.pdf

Kline, D. W., Kline, T. J. B., Fozard, J. L., Kosnik, W., Schieber, F., \& Sekuler, R. (1992). Vision, Aging, and Driving: The Problems of Older Drivers. Journal of Gerontology, 47(1), P27-P34. doi:10.1093/geronj/47.1.P27

Lamberti, R., \& De Guglielmo, M. L. (2005). Probabilistic Risk Analysis in Road Tunnel Safety. In 3rd International SIIV Congress-People, Land, Environment and Transport Infrastructures Reliability and Development, Bari, Italy. Retrieved from http://www.siiv.net/site/sites/default/files/Documenti/bari2005/024.pdf.

Levy, D. T. (1990). Youth and traffic safety: the effects of driving age, experience, and education. Accident Analysis \& Prevention, 22(4), 327-334.

Li, Z. (2000). Traffic engineering, the second edition. The People Traffic Press.

Ma, Z., Shao, C., \& Zhang, S. (2009). Characteristics of traffic accidents in Chinese freeway tunnels. Tunneling and Underground Space Technology, 24(3), 350-355.

Mackworth, N. H. (1965). Visual noise causes tunnel vision. Psychonomic Science. Retrieved from http://psycnet.apa.org/psycinfo/1965-13568-001

Marec, M. (1996). Major road tunnel project - How far can we go? Tunneling and Underground Space Technology, 11, 21-26. 
Mason, D. F. (1992). An evaluation of the quality of police report data for collisions involving heavy trucks. Retrieved from http://dspace.hil.unb.ca:8080/handle/1882/35565.

Matthews, M. L., \& Moran, A. R. (1986). Age differences in male drivers' perception of accident risk: The role of perceived driving ability. Accident Analysis \& Prevention, 18(4), 299-313.

McKelvey, F. X., Maleck, T. L., Stamatiadis, N., \& Hardy, D. K. (1988). Highway accidents and the older driver. Retrieved from http://trid.trb.org/view.aspx?id=294388.

Meng, Q., \& Qu, X. (2012). Estimation of rear-end vehicle crash frequencies in urban road tunnels. Accident Analysis \& Prevention, 48, 254-263.

Michalsky, J. J. (1988). "The astronomical almanac's" algorithm for approximate solar position (1950-2050)." Sol. Energy, 40(3), 227-235.

Mitra, S. (2008). Investigating Impact of Sun Glare on Transportation Safety. Presented at the Transportation Research Board 87th Annual Meeting. Retrieved from http://trid.trb.org/view.aspx?id=848407

Nagai, S., Ishida, S., Shinji, M., \& Nakagawa, K. (2005). Energy-saving lighting system for road tunnel. In 2005 ITA-AITES World Tunnel Congress and 31st General Assembly, May 7, 2005 - May 12, 2005 (Vol. 1, pp. 625631). A.A. Balkema Publishers. 
Owsley, C., Ball, K., Sloane, M. E., Roenker, D. L., \& Bruni, J. R. (1991).

Visual/cognitive correlates of vehicle accidents in older drivers. Psychology and Aging, 6(3), 403.

Ponds, R. W., Brouwer, W. H., \& Van Wolffelaar, P. C. (1988). Age differences in divided attention in a simulated driving task. Journal of Gerontology, 43(6), P151-P156.

Rogé, J., \& Pébayle, T. (2009). Deterioration of the useful visual field with ageing during simulated driving in traffic and its possible consequences for road safety. Safety Science, 47(9), 1271-1276.

Scialfa, C., Kline, D., Lyman, B., 1987a. Age differences in target identification as a function of retinal location and noise level: examination of the useful field of view. Psychology and Aging 2, 14-19.

Sekuler, R., Ball. K., 1986. Visual localization: age and practice. Journal of the Optical Society of America 3, 864-867.

Senior driver California Department of Motor Vehicle. (2011). Retrieved from http://www.dmv.ca.gov/about/senior/driverlicense/restrict.htm

Shengrui, Z., \& Zhuanglin, M. (2006). Traffic accident characteristics in freeway tunnels. In 5th International Conference on Traffic and Transportation Studies, ICTTS, August 2, 2006 - August 4, 2006 (pp. 771-779). American Society of Civil Engineers. 
Shi, L., Haoxue, L., Weihua, Z., (2011). "The influence of lighting zone on vision information capturing for extra-long tunnel." Highway. 2011, 6, pp. 213218

Song, F., \& Yang, X. (2009). A Study on Driver's Dynamic Visual Characteristics. In ICCTP 2009 (pp. 1-7). American Society of Civil Engineers.

State Farm. (2013). October crash rates. Retrieved from http://teendriving.statefarm.com/research-stats/october-crash-rates.

Stutts, J. C. (1998). Do older drivers with visual and cognitive impairments drive less? Journal of the American Geriatrics Society. Retrieved from http://psycnet.apa.org/psycinfo/1998-04923-003.

Sullivan, K. A., Smith, S. S., Horswill, M. S., \& Lurie-Beck, J. K. (2011). Older adults' safety perceptions of driving situations: Towards a new driving selfregulation scale. Accident Analysis \& Prevention, 43(3), 1003-1009.

Sunrise and Sunset for U.S.A. - California - Los Angeles. (2013). Retrieved December 6, 2013, from http://www.timeanddate.com/worldclock/astronomy.html?n=137\&month=1 $2 \&$ year=2013\&obj=sun\&afl=-13\&day=1.

Tasman, W., and Jaeger, E. A. (2004). Duane's clinical ophthalmology, Lippincott Williams \& Wilkins. Philadelphia. 
Traffic Injury Mapping System (TIMS) (2001-2011), Safe Transportation Research and Education Center (SafeTREC), University of California, Berkeley.

Traffic Injury Mapping System (TIMS) (2013), Safe Transportation Research and Education Center (SafeTREC), University of California, Berkeley.

"Traffic Manual - Ch. 9 - Traffic Signals and Lighting." (2006). Traffic Manual Ch. 9 - Traffic Signals and Lighting. California Department of Transportation. http://www.dot.ca.gov/hq/traffops/engineering/signdel/chp9/chap9.htm\#Se ction_11

Turner, C., \& McClure, R. (2003). Age and gender differences in risk-taking behaviour as an explanation for high incidence of motor vehicle crashes as a driver in young males. Injury Control and Safety Promotion, 10(3), $123-130$.

Vision standards (FFDL 14)-vision requirements for driving class c vehicles. (2011). Retrieved from http://www.dmv.ca.gov/pubs/brochures/fast_facts/ffdl14.htm

Vashitz, G., Shinar, D., \& Blum, Y. (2008). In-vehicle information systems to improve traffic safety in road tunnels. Transportation Research Part F: Traffic Psychology and Behaviour, 11(1), 61-74. 
U.S. Census Bureau. (2010). QT-P1- Geography-California: Age Groups and Sex: 2010. Tables P12, P13 and PCT12.

U.S.Census Bureau. (2005). Population Division, Interim State Population Projections.

Wang, H., Liu, H. X., Zhao, W.H. (2009). Analysis on traffic accident feature in expressway tunnel. Highway, 11, 144-147.

Washington, F., \& Sosseh, S. (2004). Drivers over 65 almost twice as likely as middle-age drivers to die in car crashes, according to AAA Foundation study. Retrieved from https://www.aaafoundation.org/sites/default/files/DriversOver65.pdf.

Wolfson, S. S., and Graham, N. (2000). "Exploring the dynamics of light adaptation: the effects of varying the flickering background's duration in the probed-sinewave paradigm." Vision Res., 40, 2277-2289.

Wu, D. K. H., Lin, Y. F., Pin, Y. F., \& Tsui, D. W. S. (2012). Efficient Numerical Investigation of Ventilation System Design of Road Tunnels, 283-287. doi:10.1115/IMECE2012-93124.

Yan, B., Chen, H., \& Wang, L. (n.d.). Visual Characteristics of the Driver to Tunnel Group Traffic Safety. In ICTE 2011 (pp. 3009-3014). American Society of Civil Engineers. Retrieved from http://ascelibrary.org/doi/abs/10.1061/41184\%28419\%29497. 
Yan, W., Zhong-yin, G., \& Zhi-gao, L. (2010). Safety Analysis for Illumination Design at Tunnel Entrance and Exit. In 2010 International Conference on Intelligent Computation Technology and Automation (ICICTA) (Vol. 3, pp. 255-259).

Yeung, J. S., Wong, Y. D., \& Xu, H. (2013). Driver perspectives of open and tunnel expressways. Journal of Environmental Psychology, 36, 248-256.

Yi, L., Xiang, Q., \& Len, H. (2011). Impact of lighting on traffic safety in freeway tunnel. In 11th International Conference of Chinese Transportation Professionals: Towards Sustainable Transportation Systems, ICCTP 2011, August 14, 2011 - August 17, 2011 (pp. 2358-2366). American Society of Civil Engineers (ASCE).

Zhang, S,R., Ma, Z,L., (2006). Traffic accident characteristics in freeway tunnels. In Proceeding of $5^{\text {th }}$ International Conference on Traffic and Transportation Studies, pp. 771-779.

Zhao, J., He, C., \& hi, Y. (2009). Research on the Impact of Divers' Heart Rate on Longitudinal Slope of Freeway Tunnel. In ICCTP 2009 (pp. 1-8). American Society of Civil Engineers. Retrieved from http://ascelibrary.org/doi/abs/10.1061/41064\%28358\%2957.

Zhao, L., Jiang, H.-P., \& Hu, J.-B. (2011). Driver's physiological and mental reaction in tunnel. In 11th International Conference of Chinese Transportation Professionals: Towards Sustainable Transportation 
Systems, ICCTP 2011, August 14, 2011 - August 17, 2011 (pp. 17601766). American Society of Civil Engineers (ASCE).

doi:10.1061/41186(421)174.

Zhao, W., \& Liu, H. (2011). Drivers' Visual Feature Variation in Long-Tunnel Exit of Expressway. In ICTIS 2011 (pp. 45-52). American Society of Civil Engineers. Retrieved from http://ascelibrary.org/doi/abs/10.1061/41177\%28415\%2 


\section{APPENDICES}

Page | 79 


\section{A. Population Projections}

\begin{tabular}{|c|c|c|c|c|c|c|c|c|c|c|c|c|c|c|c|c|}
\hline & \multicolumn{4}{|c|}{2000} & \multicolumn{4}{|c|}{2010} & \multicolumn{4}{|c|}{2020} & \multicolumn{4}{|c|}{2030} \\
\hline Age & Male & Female & Male & $\begin{array}{l}\text { Femal } \\
\mathrm{e}\end{array}$ & Male & Female & Male & $\begin{array}{l}\text { Femal } \\
\mathrm{e}\end{array}$ & Male & Female & $\begin{array}{l}\text { Mal } \\
\mathrm{e}\end{array}$ & $\begin{array}{l}\text { Femal } \\
\mathrm{e}\end{array}$ & Male & Female & $\begin{array}{l}\text { Mal } \\
\mathrm{e}\end{array}$ & $\begin{array}{l}\text { Femal } \\
\mathrm{e}\end{array}$ \\
\hline $10-19$ & 258876 & 243294 & & & 269373 & 254914 & & & 275308 & 262521 & & & 310882 & 296349 & 0.07 & \\
\hline Yrs & 1 & 9 & 0.09 & 0.08 & 6 & 6 & 0.08 & 0.08 & 9 & 6 & 0.08 & 0.07 & 3 & 7 & 7 & 0.07 \\
\hline $20-29$ & 255697 & 236785 & & & 298598 & 282106 & & & 307757 & \begin{tabular}{|l|}
290031 \\
\end{tabular} & & & 324030 & 306324 & 0.08 & \\
\hline Yrs & 5 & 4 & 0.09 & 0.08 & 3 & 8 & 0.09 & 0.09 & 0 & 4 & 0.09 & 0.08 & 4 & 1 & 1 & 0.08 \\
\hline $30-39$ & 281264 & 268761 & & & 260413 & 254434 & & & 310793 & 301336 & & & 328175 & 315181 & 0.08 & \\
\hline Yrs & 8 & 6 & 0.10 & 0.09 & 8 & 0 & 0.08 & 0.08 & 4 & 7 & 0.09 & 0.08 & 4 & 5 & 2 & 0.08 \\
\hline $40-49$ & 249515 & 250723 & & & 269914 & 268653 & & & 249445 & \begin{tabular}{|l|}
251699 \\
\end{tabular} & & & 304704 & 302493 & 0.07 & \\
\hline $50-59$ & 169200 & 177508 & & & 234535 & 244715 & & & 249822 & \begin{tabular}{|l|}
257486 \\
\end{tabular} & & & 232826 & 243308 & 0.05 & \\
\hline Yrs & 7 & 8 & 0.06 & 0.06 & 6 & 4 & 0.07 & 0.07 & 2 & 2 & 0.07 & 0.07 & 3 & 8 & 8 & 0.06 \\
\hline $60-69$ & 100288 & 112849 & & & 150395 & 169170 & & & 204757 & \begin{tabular}{|l|}
227872 \\
\end{tabular} & & & 218627 & 240747 & 0.05 & \\
\hline Yrs & 1 & 5 & 0.03 & 0.04 & 6 & 9 & 0.05 & 0.05 & 4 & 1 & 0.06 & 0.06 & 9 & 0 & 4 & 0.06 \\
\hline $70-79$ & & & & & & & & & 119499 & 148443 & & & 164665 & 201939 & 0.04 & \\
\hline Yrs & 725610 & 957025 & 0.03 & 0.03 & 788232 & 987334 & 0.02 & 0.03 & 9 & 6 & 0.03 & 0.04 & 6 & 8 & 1 & 0.05 \\
\hline $\begin{array}{l}80 \mathrm{Yrs} \\
\text { and } \\
\text { over }\end{array}$ & 3 & & 01 & 0.02 & & 91 & 1 & 2 & 97 & 965479 & 002 & 03 & 22 & 143904 & 0.02 & 004 \\
\hline over & & $\begin{array}{l}597000 \\
286587\end{array}$ & 01 & 0.02 & & $\begin{array}{l}813691 \\
326301\end{array}$ & 11 & 2 & & \begin{tabular}{|l}
$9654 / 9$ \\
361105
\end{tabular} & 0.02 & 03 & & $\begin{array}{r}6 \\
402385\end{array}$ & & 0.04 \\
\hline
\end{tabular}

Source: U.S. Census Bureau, Population Division, Interim State Population Projections, 2005. Internet Release: 2005 


\section{B. Crash Characteristics}

\section{YEARLY}

\begin{tabular}{|l|r|}
\hline Year & Count \\
\hline 2002 & 105 \\
\hline 2003 & 104 \\
\hline 2004 & 100 \\
\hline 2005 & 105 \\
\hline 2006 & 91 \\
\hline 2007 & 109 \\
\hline 2008 & 88 \\
\hline 2009 & 99 \\
\hline 2010 & 85 \\
\hline 2011 & 82 \\
\hline
\end{tabular}

MONTHLY

\begin{tabular}{|l|r|}
\hline Month & Count \\
\hline January & 65 \\
\hline February & 79 \\
\hline March & 79 \\
\hline April & 75 \\
\hline May & 81 \\
\hline June & 77 \\
\hline July & 79 \\
\hline August & 99 \\
\hline September & 67 \\
\hline October & 92 \\
\hline November & 85 \\
\hline December & 90 \\
\hline
\end{tabular}




\section{HOURLY}

\section{Percentage}

\begin{tabular}{|c|c|c|c|c|c|}
\hline Time & $\begin{array}{l}\text { Under } 25 \\
\text { Yrs }\end{array}$ & $\begin{array}{l}26-29 \\
\text { Yrs }\end{array}$ & $\begin{array}{l}30-45 \\
\text { Yrs }\end{array}$ & $\begin{array}{l}46-59 \\
\text { Yrs }\end{array}$ & $\begin{array}{l}\text { Over } \\
60 \text { Yrs }\end{array}$ \\
\hline 1:00 AM & $5 \%$ & $4 \%$ & $1 \%$ & $2 \%$ & $0 \%$ \\
\hline 2:00 AM & $11 \%$ & $10 \%$ & $3 \%$ & $1 \%$ & $0 \%$ \\
\hline 3:00 AM & $5 \%$ & $5 \%$ & $2 \%$ & $0 \%$ & $1 \%$ \\
\hline 4:00 AM & $5 \%$ & $2 \%$ & $1 \%$ & $2 \%$ & $0 \%$ \\
\hline 5:00 AM & $3 \%$ & $3 \%$ & $3 \%$ & $0 \%$ & $4 \%$ \\
\hline 6:00 AM & $1 \%$ & $3 \%$ & $3 \%$ & $6 \%$ & $7 \%$ \\
\hline 7:00 AM & $3 \%$ & $6 \%$ & $4 \%$ & $6 \%$ & $6 \%$ \\
\hline $8: 00 \mathrm{AM}$ & $2 \%$ & $2 \%$ & $2 \%$ & $7 \%$ & $1 \%$ \\
\hline 9:00 AM & $4 \%$ & $3 \%$ & $6 \%$ & $5 \%$ & $1 \%$ \\
\hline 10:00 AM & $3 \%$ & $0 \%$ & $5 \%$ & $6 \%$ & $9 \%$ \\
\hline $11: 00$ AM & $2 \%$ & $4 \%$ & $8 \%$ & $6 \%$ & $10 \%$ \\
\hline 12:00 PM & $5 \%$ & $3 \%$ & $4 \%$ & $8 \%$ & $3 \%$ \\
\hline 1:00 PM & $6 \%$ & $3 \%$ & $4 \%$ & $5 \%$ & $6 \%$ \\
\hline 2:00 PM & $3 \%$ & $7 \%$ & $7 \%$ & $5 \%$ & $7 \%$ \\
\hline $3: 00 \mathrm{PM}$ & $5 \%$ & $7 \%$ & $4 \%$ & $6 \%$ & $4 \%$ \\
\hline 4:00 PM & $3 \%$ & $4 \%$ & $6 \%$ & $7 \%$ & $10 \%$ \\
\hline 5:00 PM & $6 \%$ & $7 \%$ & $7 \%$ & $7 \%$ & $9 \%$ \\
\hline 6:00 PM & $5 \%$ & $7 \%$ & $8 \%$ & $5 \%$ & $7 \%$ \\
\hline 7:00 PM & $5 \%$ & $3 \%$ & $4 \%$ & $4 \%$ & $4 \%$ \\
\hline $8: 00 \mathrm{PM}$ & $3 \%$ & $3 \%$ & $3 \%$ & $2 \%$ & $0 \%$ \\
\hline 9:00 PM & $3 \%$ & $4 \%$ & $2 \%$ & $4 \%$ & $4 \%$ \\
\hline 10:00 PM & $6 \%$ & $2 \%$ & $3 \%$ & $1 \%$ & $1 \%$ \\
\hline 11:00 PM & $2 \%$ & $5 \%$ & $6 \%$ & $2 \%$ & $0 \%$ \\
\hline 12:00 AM & $4 \%$ & $2 \%$ & $2 \%$ & $2 \%$ & $0 \%$ \\
\hline Total & $100 \%$ & $100 \%$ & $100 \%$ & $100 \%$ & $100 \%$ \\
\hline
\end{tabular}


Count

\begin{tabular}{|r|r|r|r|r|r|r|}
\hline \multicolumn{1}{l|}{ Time } & \multicolumn{1}{l|l}{$\begin{array}{l}\text { Under } \\
\text { 25 }\end{array}$} & $\begin{array}{l}\text { Yrs } \\
\text { Yrs }\end{array}$ & $\begin{array}{l}\text { Yrs } \\
\text { Yrs }\end{array}$ & $\begin{array}{l}\text { Yver } 60 \\
\text { Yrs }\end{array}$ & Total \\
\hline 1:00 AM & 14 & 5 & 4 & 3 & 0 & 26 \\
\hline 2:00 AM & 29 & 12 & 8 & 2 & 0 & 51 \\
\hline 3:00 AM & 12 & 6 & 7 & 0 & 1 & 26 \\
\hline 4:00 AM & 12 & 2 & 4 & 3 & 0 & 21 \\
\hline 5:00 AM & 8 & 3 & 10 & & 3 & 24 \\
\hline 6:00 AM & 3 & 3 & 10 & 9 & 5 & 30 \\
\hline 7:00 AM & 7 & 7 & 13 & 9 & 4 & 40 \\
\hline 8:00 AM & 6 & 2 & 7 & 10 & 1 & 26 \\
\hline 9:00 AM & 10 & 4 & 19 & 8 & 1 & 42 \\
\hline 10:00 AM & 9 & 0 & 14 & 9 & 6 & 38 \\
\hline 11:00 AM & 5 & 5 & 23 & 9 & 7 & 49 \\
\hline 12:00 PM & 13 & 3 & 13 & 12 & 2 & 43 \\
\hline 1:00 PM & 17 & 3 & 12 & 7 & 4 & 43 \\
\hline 2:00 PM & 7 & 8 & 21 & 7 & 5 & 48 \\
\hline 3:00 PM & 13 & 8 & 13 & 9 & 3 & 46 \\
\hline 4:00 PM & 9 & 5 & 17 & 11 & 7 & 49 \\
\hline 5:00 PM & 15 & 8 & 22 & 10 & 6 & 61 \\
\hline 6:00 PM & 13 & 8 & 23 & 7 & 5 & 56 \\
\hline 7:00 PM & 14 & 4 & 12 & 6 & 3 & 39 \\
\hline 8:00 PM & 8 & 4 & 9 & 3 & 0 & 24 \\
\hline 9:00 PM & 8 & 5 & 6 & 6 & 3 & 28 \\
\hline 10:00 PM & 17 & 2 & 9 & 2 & 1 & 31 \\
\hline 11:00 PM & 6 & 6 & 17 & 3 & 0 & 32 \\
\hline 12:00 AM & 11 & 2 & 6 & 3 & 0 & 22 \\
\hline Total & 266 & 115 & 299 & 148 & 67 & 896 \\
\hline
\end{tabular}




\section{LIGHTING}

Percentage

\begin{tabular}{|l|c|c|c|c|c|}
\hline Lighting & $\begin{array}{l}\text { Under } \\
25 \text { Yrs }\end{array}$ & $\begin{array}{l}26-29 \\
\text { Yrs }\end{array}$ & $\begin{array}{l}30-45 \\
\text { Yrs }\end{array}$ & $\begin{array}{l}46-59 \\
\text { Yrs }\end{array}$ & $\begin{array}{l}\text { Over 60 } \\
\text { Yrs }\end{array}$ \\
\hline Daylight & $45 \%$ & $48 \%$ & $63 \%$ & $72 \%$ & $77 \%$ \\
\hline Dusk - Dawn & $3 \%$ & $3 \%$ & $3 \%$ & $2 \%$ & $6 \%$ \\
\hline $\begin{array}{l}\text { Dark - Street } \\
\text { Lights }\end{array}$ & $50 \%$ & $42 \%$ & $31 \%$ & $24 \%$ & $15 \%$ \\
\hline $\begin{array}{l}\text { Dark - No Street } \\
\text { Lights }\end{array}$ & $2 \%$ & $7 \%$ & $3 \%$ & $2 \%$ & $2 \%$ \\
\hline Total & $100 \%$ & $100 \%$ & $100 \%$ & $100 \%$ & $100 \%$ \\
\hline
\end{tabular}

Count

\begin{tabular}{|l|r|l|l|l|l|r|}
\hline Lighting & $\begin{array}{l}\text { Under } \\
\text { 25 Yrs }\end{array}$ & $\begin{array}{l}\text { Yrs } \\
\text { Yrs }\end{array}$ & $\begin{array}{l}\text { l0-45 } \\
\text { Yrs }\end{array}$ & $\begin{array}{l}\text { l6-59 } \\
\text { Yrs }\end{array}$ & $\begin{array}{l}\text { Over 60 } \\
\text { Yrs }\end{array}$ & \multicolumn{1}{l|}{ Total } \\
\hline Daylight & 119 & 55 & 187 & 107 & 51 & 519 \\
\hline Dusk - Dawn & 7 & 4 & 10 & 3 & 4 & 28 \\
\hline $\begin{array}{l}\text { Dark - Street } \\
\text { Lights }\end{array}$ & 132 & 48 & 92 & 36 & 10 & 318 \\
\hline $\begin{array}{l}\text { Dark - No } \\
\text { Street Lights }\end{array}$ & 4 & 8 & 8 & 3 & 1 & 24 \\
\hline Total & 262 & 115 & 297 & 149 & 66 & 889 \\
\hline
\end{tabular}

\section{TUNNEL LOCATION}

\section{Percentage}

\begin{tabular}{|l|c|c|c|c|c|c|}
\hline Location & $\begin{array}{c}\text { Under 25 } \\
\text { Yrs }\end{array}$ & $26-29$ Yrs & $30-45$ Yrs & $46-59$ Yrs & $\begin{array}{c}\text { Over } 60 \\
\text { Yrs }\end{array}$ & Total \\
\hline Entrance & $35 \%$ & $40 \%$ & $34 \%$ & $42 \%$ & $34 \%$ & $36 \%$ \\
\hline Tunnel & $40 \%$ & $34 \%$ & $35 \%$ & $38 \%$ & $52 \%$ & $38 \%$ \\
\hline Exit & $25 \%$ & $26 \%$ & $32 \%$ & $20 \%$ & $14 \%$ & $26 \%$ \\
\hline Total & $100 \%$ & $100 \%$ & $100 \%$ & $100 \%$ & $100 \%$ & $100 \%$ \\
\hline
\end{tabular}

Count

\begin{tabular}{|l|c|c|c|c|c|c|}
\hline Location & $\begin{array}{c}\text { Under 25 } \\
\text { Yrs }\end{array}$ & $26-29$ Yrs & $30-45$ Yrs & $46-59$ Yrs & $\begin{array}{c}\text { Over 60 } \\
\text { Yrs }\end{array}$ & Total \\
\hline Entrance & 83 & 44 & 92 & 59 & 20 & 298 \\
\hline Tunnel & 95 & 37 & 95 & 54 & 30 & 311 \\
\hline Exit & 60 & 29 & 86 & 28 & 8 & 211 \\
\hline Total & 238 & 110 & 273 & 141 & 58 & 820 \\
\hline
\end{tabular}




\section{Chi-square}

\begin{tabular}{|l|c|c|c|c|c|c|c|c|c|c|c|}
\hline \multirow{2}{*}{ Location } & \multicolumn{2}{|c|}{ Under 25 Yrs } & \multicolumn{2}{c|}{$26-29$ Yrs } & \multicolumn{2}{c|}{$30-45$ Yrs } & \multicolumn{2}{c|}{$46-50$ Yrs } & \multicolumn{2}{c|}{ 0ver 60 Yrs } & \multirow{2}{*}{ Total } \\
\cline { 2 - 12 } & Observe & Expected & Observe & Expecte & Observe & Expected & Observe & Expected Observe & Expected & \\
\hline Entrance & 83 & 86 & 44 & 40 & 92 & 99 & 59 & 51 & 20 & 21 & 298 \\
\hline Tunnel & 95 & 90 & 37 & 42 & 95 & 104 & 54 & 53 & 30 & 22 & 311 \\
\hline Exit & 60 & 61 & 29 & 28 & 86 & 70 & 28 & 36 & 8 & 15 & 211 \\
\hline Total & 238 & & 110 & & 273 & & 141 & & 58 & 820 \\
\hline
\end{tabular}

\begin{tabular}{|c|c|c|c|c|}
\hline Fo & fe & (fo-fe) & $(\text { fo-fe })^{\wedge} 2$ & $\begin{array}{l}\text { ((fo- } \\
\left.\text { fe })^{\wedge} 2\right) / f e\end{array}$ \\
\hline 83 & 86 & 0 & 12 & 0 \\
\hline 95 & 90 & 0 & 22 & 0 \\
\hline 60 & 61 & 0 & 2 & 0 \\
\hline 44 & 40 & 0 & 16 & 0 \\
\hline 37 & 42 & 1 & 22 & 1 \\
\hline 29 & 28 & 0 & 0 & 0 \\
\hline 92 & 99 & 1 & 52 & 1 \\
\hline 95 & 104 & 1 & 73 & 1 \\
\hline 86 & 70 & 4 & 248 & 4 \\
\hline 59 & 51 & 1 & 60 & 1 \\
\hline 54 & 53 & 0 & 0 & 0 \\
\hline 28 & 36 & 2 & 69 & 2 \\
\hline 20 & 21 & 0 & 1 & 0 \\
\hline 30 & 22 & 3 & 64 & 3 \\
\hline 8 & 15 & 3 & 48 & 3 \\
\hline \multicolumn{4}{|c|}{$\Sigma$ Chi-square $X^{\wedge} 2$} & 15 \\
\hline \multicolumn{4}{|c|}{ Degrees of Freedom $=(\mathrm{r}-1)(\mathrm{c}-1)$} & 8 \\
\hline \multicolumn{4}{|c|}{ P-Value (right tail) } & 0.059 \\
\hline
\end{tabular}




\section{COLLISION TYPE}

Percentage

\begin{tabular}{|c|c|c|c|c|c|c|}
\hline Type & $\begin{array}{l}\text { Under } \\
25 \text { Yrs }\end{array}$ & $26-29$ Yrs & $30-45$ Yrs & $46-59$ Yrs & $\begin{array}{c}\text { Over } 60 \\
\text { Yrs }\end{array}$ & Total \\
\hline Sideswipe & $15 \%$ & $11 \%$ & $13 \%$ & $11 \%$ & $23 \%$ & $14 \%$ \\
\hline Rear-end & $53 \%$ & $65 \%$ & $68 \%$ & $75 \%$ & $60 \%$ & $64 \%$ \\
\hline Broadside & $1 \%$ & $2 \%$ & $2 \%$ & $2 \%$ & $2 \%$ & $2 \%$ \\
\hline Hit Object & $31 \%$ & $21 \%$ & $16 \%$ & $11 \%$ & $16 \%$ & $21 \%$ \\
\hline Total & $100 \%$ & $100 \%$ & $100 \%$ & $100 \%$ & $100 \%$ & $100 \%$ \\
\hline
\end{tabular}

Count

\begin{tabular}{|c|c|c|c|c|c|c|}
\hline Type & $\begin{array}{l}\text { Under } \\
25 \text { Yrs }\end{array}$ & $26-29$ Yrs & $30-45$ Yrs & 46-59 Yrs & $\begin{array}{c}\text { Over } 60 \\
\text { Yrs }\end{array}$ & Total \\
\hline Sideswipe & 39 & 12 & 36 & 16 & 14 & 117 \\
\hline Rearend & 133 & 70 & 187 & 107 & 37 & 534 \\
\hline Broadside & 3 & 2 & 5 & 3 & 1 & 14 \\
\hline Hit Object & 78 & 23 & 45 & 16 & 10 & 172 \\
\hline Total & 253 & 107 & 273 & 142 & 62 & 837 \\
\hline
\end{tabular}




\section{Driver and Party Characteristics}

\section{SEX}

Percentage

\begin{tabular}{|l|r|r|r|r|r|r|}
\hline Sex & $\begin{array}{c}\text { Under } 25 \\
\text { Yrs }\end{array}$ & $26-29$ Yrs & $30-45$ Yrs & $46-59$ Yrs & 0ver 60 Yrs & Total \\
\hline Female & $38 \%$ & $38 \%$ & $25 \%$ & $23 \%$ & $25 \%$ & $30 \%$ \\
\hline Male & $62 \%$ & $62 \%$ & $75 \%$ & $77 \%$ & $75 \%$ & $70 \%$ \\
\hline Total & $100 \%$ & $100 \%$ & $100 \%$ & $100 \%$ & $100 \%$ & $100 \%$ \\
\hline
\end{tabular}

Count

\begin{tabular}{|l|r|r|r|r|r|r|}
\hline Sex & $\begin{array}{c}\text { Under 25 } \\
\text { Yrs }\end{array}$ & 26-29 Yrs & 30-45 Yrs & 46-59 Yrs & 0ver 60 Yrs & Total \\
\hline Female & 101 & 44 & 74 & 34 & 17 & 270 \\
\hline Male & 164 & 71 & 225 & 115 & 50 & 625 \\
\hline Total & 265 & 115 & 299 & 149 & 67 & 895 \\
\hline
\end{tabular}

\section{VIOLATION CATEGORY}

Percentage

\begin{tabular}{|l|r|r|r|r|r|r|}
\hline Violation & $\begin{array}{r}\text { Under } \\
25 \text { Yrs }\end{array}$ & $\begin{array}{c}\text { Yrs } \\
\text { Yrs }\end{array}$ & $\begin{array}{c}\text { Yo-45 } \\
\text { Yrs }\end{array}$ & \multicolumn{1}{c|}{$\begin{array}{c}\text { Y6-59 } \\
\text { Yrs }\end{array}$} & $\begin{array}{c}\text { Over 60 } \\
\text { Yrs }\end{array}$ & Total \\
\hline DUI & $18 \%$ & $19 \%$ & $12 \%$ & $6 \%$ & $7 \%$ & $13 \%$ \\
\hline Unsafe Speed & $55 \%$ & $61 \%$ & $54 \%$ & $64 \%$ & $48 \%$ & $57 \%$ \\
\hline $\begin{array}{l}\text { Following Too } \\
\text { Closely }\end{array}$ & $5 \%$ & $6 \%$ & $13 \%$ & $11 \%$ & $3 \%$ & $9 \%$ \\
\hline $\begin{array}{l}\text { Unsafe Lane } \\
\text { Change }\end{array}$ & $9 \%$ & $6 \%$ & $13 \%$ & $12 \%$ & $28 \%$ & $12 \%$ \\
\hline Improper Turning & $12 \%$ & $7 \%$ & $9 \%$ & $6 \%$ & $14 \%$ & $10 \%$ \\
\hline Total & $100 \%$ & $100 \%$ & $100 \%$ & $100 \%$ & $100 \%$ & $100 \%$ \\
\hline
\end{tabular}


Count

\begin{tabular}{|c|c|c|c|c|c|c|}
\hline Violation & $\begin{array}{l}\text { Under } \\
25 \text { Yrs }\end{array}$ & $\begin{array}{c}26-29 \\
\text { Yrs }\end{array}$ & $\begin{array}{c}30-45 \\
\text { Yrs }\end{array}$ & $\begin{array}{c}46-59 \\
\text { Yrs }\end{array}$ & $\begin{array}{c}\text { Over } 60 \\
\text { Yrs }\end{array}$ & Total \\
\hline DUI & 47 & 21 & 33 & 9 & 4 & 114 \\
\hline Unsafe Speed & 143 & 67 & 150 & 90 & 28 & 478 \\
\hline $\begin{array}{l}\text { Following Too } \\
\text { Closely }\end{array}$ & 14 & 6 & 37 & 15 & 2 & 74 \\
\hline $\begin{array}{l}\text { Unsafe Lane } \\
\text { Change }\end{array}$ & 23 & 7 & 35 & 17 & 16 & 98 \\
\hline Improper Turning & 32 & 8 & 25 & 9 & 8 & 82 \\
\hline Total & 259 & 109 & 280 & 140 & 58 & 846 \\
\hline
\end{tabular}

\section{SEVERITY}

\section{Percentage}

\begin{tabular}{|c|c|c|c|c|c|c|}
\hline Severity & $\begin{array}{l}\text { Under } 25 \\
\text { Yrs }\end{array}$ & 26-29 Yrs & $30-45$ Yrs & 46-59 Yrs & $\begin{array}{l}\text { Over } 60 \\
\text { Yrs }\end{array}$ & Total \\
\hline Killed & $0 \%$ & $1 \%$ & $3 \%$ & $1 \%$ & $1 \%$ & $1 \%$ \\
\hline Severe Injury & $4 \%$ & $3 \%$ & $3 \%$ & $5 \%$ & $3 \%$ & $3 \%$ \\
\hline $\begin{array}{l}\text { Other Visible } \\
\text { Injury }\end{array}$ & $35 \%$ & $30 \%$ & $22 \%$ & $21 \%$ & $24 \%$ & $27 \%$ \\
\hline $\begin{array}{l}\text { Complaint of } \\
\text { Pain }\end{array}$ & $61 \%$ & $65 \%$ & $73 \%$ & $72 \%$ & $72 \%$ & $68 \%$ \\
\hline Total & $100 \%$ & $100 \%$ & $100 \%$ & $100 \%$ & $100 \%$ & $100 \%$ \\
\hline
\end{tabular}

\section{Count}

\begin{tabular}{|c|c|c|c|c|c|c|}
\hline Severity & $\begin{array}{l}\text { Under } 25 \\
\text { Yrs }\end{array}$ & $26-29$ Yrs & $30-45$ Yrs & 46-59 Yrs & $\begin{array}{l}\text { Over } 60 \\
\text { Yrs }\end{array}$ & Total \\
\hline Killed & 0 & 1 & 9 & 2 & 1 & 13 \\
\hline Severe Injury & 10 & 4 & 8 & 7 & 2 & 31 \\
\hline $\begin{array}{l}\text { Other Visible } \\
\text { Injury }\end{array}$ & 94 & 35 & 65 & 32 & 16 & 242 \\
\hline $\begin{array}{l}\text { Complaint of } \\
\text { Pain }\end{array}$ & 162 & 75 & 217 & 108 & 48 & 610 \\
\hline Total & 266 & 115 & 299 & 149 & 67 & 896 \\
\hline
\end{tabular}




\section{Chi-square}

\begin{tabular}{|c|c|c|c|c|c|c|c|c|c|c|c|}
\hline \multirow{2}{*}{ Sobriety } & \multicolumn{2}{|c|}{ Under 25 Yrs } & \multicolumn{2}{|c|}{$26-29$ Yrs } & \multicolumn{2}{|c|}{$30-45$ Yrs } & \multicolumn{2}{|c|}{$46-50 \mathrm{Yrs}$} & \multicolumn{2}{|c|}{ Over 60 Yrs } & \multirow{2}{*}{ Total } \\
\hline & Observed & Expected & Observed & Expected & Observed & Expected & Observed & Expected & Observed & Expected & \\
\hline Killed & 0 & 4 & 1 & 2 & 9 & 4 & 2 & 2 & 1 & 1 & 13 \\
\hline Severe Injury & 10 & 9 & 4 & 4 & 8 & 10 & 7 & 5 & 2 & 2 & 31 \\
\hline Other Visible Injury & 94 & 72 & 35 & 31 & 65 & 81 & 32 & 40 & 16 & 18 & 242 \\
\hline Complaint of Pain & 162 & 181 & 75 & 78 & 217 & 204 & 108 & 101 & 48 & 46 & 610 \\
\hline Total & 266 & & 115 & & 299 & & 149 & & 67 & & 896 \\
\hline
\end{tabular}

\begin{tabular}{|c|c|c|c|c|}
\hline Fo & fe & (fo-fe) & $\begin{array}{l}\text { (fo- } \\
\text { fe)^2 }\end{array}$ & $\left((f o-f e)^{\wedge} 2\right) / f e$ \\
\hline 0 & 4 & 4 & 15 & 4 \\
\hline 10 & 9 & 0 & 1 & 0 \\
\hline 94 & 72 & 7 & 491 & 7 \\
\hline 162 & 181 & 2 & 365 & 2 \\
\hline 1 & 2 & 0 & 0 & 0 \\
\hline 4 & 4 & 0 & 0 & 0 \\
\hline 35 & 31 & 0 & 16 & 0 \\
\hline 75 & 78 & 0 & 11 & 0 \\
\hline 9 & 4 & 5 & 22 & 5 \\
\hline 8 & 10 & 1 & 5 & 1 \\
\hline 65 & 81 & 3 & 248 & 3 \\
\hline 217 & 204 & 1 & 181 & 1 \\
\hline 2 & 2 & 0 & 0 & 0 \\
\hline 7 & 5 & 1 & 3 & 1 \\
\hline 32 & 40 & 2 & 68 & 2 \\
\hline 108 & 101 & 0 & 43 & 0 \\
\hline 1 & 1 & 0 & 0 & 0 \\
\hline 2 & 2 & 0 & 0 & 0 \\
\hline 16 & 18 & 0 & 4 & 0 \\
\hline 48 & 46 & 0 & 6 & 0 \\
\hline \multicolumn{4}{|c|}{$\Sigma$ Chi-square $X^{\wedge} 2$} & 26 \\
\hline \multicolumn{4}{|c|}{ Degrees of Freedom $=(r-1)(c-1)$} & 12 \\
\hline \multicolumn{4}{|c|}{ P-Value (right tail) } & 0.027 \\
\hline
\end{tabular}




\section{SOBRIETY}

\section{Percentage}

\begin{tabular}{|c|c|c|c|c|c|}
\hline Sobriety & $\begin{array}{l}\text { Under } 25 \\
\text { Yrs }\end{array}$ & $26-29$ Yrs & $30-45$ Yrs & 46-59 Yrs & $\begin{array}{l}\text { Over } 60 \\
\text { Yrs }\end{array}$ \\
\hline $\begin{array}{l}\text { Had Not Been } \\
\text { Drinking }\end{array}$ & $80 \%$ & $77 \%$ & $85 \%$ & $92 \%$ & $94 \%$ \\
\hline $\begin{array}{l}\text { Had Been } \\
\text { Drinking, } \\
\text { Under } \\
\text { Influence }\end{array}$ & $17 \%$ & $19 \%$ & $13 \%$ & $5 \%$ & $6 \%$ \\
\hline $\begin{array}{l}\text { Had Been } \\
\text { Drinking, Not } \\
\text { Under } \\
\text { Influence }\end{array}$ & $4 \%$ & $5 \%$ & $2 \%$ & $3 \%$ & $0 \%$ \\
\hline Total & $100 \%$ & $100 \%$ & $100 \%$ & $100 \%$ & $100 \%$ \\
\hline
\end{tabular}

Count

\begin{tabular}{|c|c|c|c|c|c|c|}
\hline Sobriety & $\begin{array}{l}\text { Under } \\
25 \mathrm{Yrs}\end{array}$ & $\begin{array}{l}26-29 \\
\text { Yrs }\end{array}$ & $\begin{array}{l}30-45 \\
\text { Yrs }\end{array}$ & $\begin{array}{l}46-59 \\
\text { Yrs }\end{array}$ & $\begin{array}{l}\text { Over } 60 \\
\text { Yrs }\end{array}$ & Total \\
\hline $\begin{array}{l}\text { Had Not } \\
\text { Been } \\
\text { Drinking }\end{array}$ & 198 & 82 & 243 & 125 & 60 & 708 \\
\hline $\begin{array}{l}\text { Had Been } \\
\text { Drinking, } \\
\text { Under } \\
\text { Influence }\end{array}$ & 42 & 20 & 37 & 7 & 4 & 110 \\
\hline $\begin{array}{l}\text { Had Been } \\
\text { Drinking, } \\
\text { Not Under } \\
\text { Influence }\end{array}$ & 9 & 5 & 7 & 4 & & 25 \\
\hline Total & 249 & 107 & 287 & 136 & 64 & 843 \\
\hline
\end{tabular}




\section{Chi-square test}

\begin{tabular}{|c|c|c|c|c|c|c|c|c|c|c|c|}
\hline \multirow{2}{*}{ Sobriety } & \multicolumn{2}{|c|}{ Under 25 Yrs } & \multicolumn{2}{|c|}{$26-29$ Yrs } & \multicolumn{2}{|c|}{$30-45$ Yrs } & \multicolumn{2}{|c|}{$46-50$ Yrs } & \multicolumn{2}{|c|}{ Over 60 Yrs } & \multirow{2}{*}{ Total } \\
\hline & Observed & Expected & Observed & Expected & Observed & Expected & Observed & Expected & Observed & Expected & \\
\hline Had Not Been Drinking & 198 & 209 & 82 & 90 & 243 & 241 & 125 & 114 & 60 & 54 & 708 \\
\hline $\begin{array}{l}\text { Had Been Drinking, } \\
\text { Under Influence }\end{array}$ & 42 & 32 & 20 & 14 & 37 & 37 & 7 & 18 & 4 & 8 & 110 \\
\hline $\begin{array}{l}\text { Had Been Drinking, Not } \\
\text { Under Influence } \\
\end{array}$ & 9 & 7 & 5 & 3 & 7 & 9 & 4 & 4 & 0 & 2 & 25 \\
\hline Total & 249 & & 107 & & 287 & & 136 & & 64 & & 843 \\
\hline
\end{tabular}

\begin{tabular}{|c|c|c|c|c|}
\hline Fo & fe & (fo-fe) & (fo-fe)^2 & $\left((\mathrm{fo}-\mathrm{fe})^{\wedge} \mathbf{2}\right) / \mathrm{fe}$ \\
\hline 198 & 209 & 1 & 121 & 1 \\
\hline 42 & 32 & 3 & 100 & 3 \\
\hline 9 & 7 & 1 & 4 & 1 \\
\hline 82 & 90 & 1 & 62 & 1 \\
\hline 20 & 14 & 3 & 36 & 3 \\
\hline 5 & 3 & 1 & 3 & 1 \\
\hline 243 & 241 & 0 & 4 & 0 \\
\hline 37 & 37 & 0 & 0 & 0 \\
\hline 7 & 9 & 0 & 2 & 0 \\
\hline 125 & 114 & 1 & 116 & 1 \\
\hline 7 & 18 & 7 & 115 & 7 \\
\hline 4 & 4 & 0 & 0 & 0 \\
\hline 60 & 54 & 1 & 39 & 1 \\
\hline 4 & 8 & 2 & 19 & 2 \\
\hline 0 & 2 & 2 & 4 & 2 \\
\hline \multicolumn{4}{|c|}{$\Sigma$ Chi-square $X^{\wedge} 2$} & 21 \\
\hline \multicolumn{4}{|c|}{ Degrees of Freedom $=(r-1)(c-1)$} & 8 \\
\hline \multicolumn{4}{|c|}{ P-Value (right tail) } & 0.007 \\
\hline
\end{tabular}




\section{Population Proportion Analysis}

\begin{tabular}{|c|c|c|c|c|}
\hline Age in years & LA & BAY & $\begin{array}{l}\text { Crash } \\
\text { LA }\end{array}$ & $\begin{array}{l}\text { Crash } \\
\text { Bay }\end{array}$ \\
\hline 15 to 19 & 576662 & 156440 & 24 & \\
\hline 20 to 29 & 1928704 & 586347 & 86 & 20 \\
\hline 30 to 39 & 1900659 & 654701 & 45 & \\
\hline 40 to 49 & 1887349 & 666419 & 41 & \\
\hline 50 to 59 & 1534359 & 583609 & 22 & \\
\hline 60 to 69 & 945660 & 372675 & 13 & \\
\hline 70 to 79 & 569249 & 215347 & 2 & \\
\hline 30 and o & 396553 & 159336 & 3 & \\
\hline otal & 9739194 & 3394873 & 236 & 6 \\
\hline
\end{tabular}

$G=\left|1-\sum_{k=1}^{n}\left(X_{k}-X_{k-1}\right)\left(Y_{k}+Y_{k-1}\right)\right|$

G: Gini coefficient

$X_{K}$ : cumulated proportion of the population variable, for $k=0, \ldots, n$, with $X_{0}=0, X_{n}=1$

$Y_{k}$ : cumulated proportion of the income variable, for $k=0, \ldots, n$, with $Y_{0}=0, Y_{n}=1$

Source: http://en.wikipedia.org/wiki/Gini_coefficient 


\begin{tabular}{|c|c|c|c|c|c|c|c|c|c|c|c|}
\hline \multicolumn{2}{|c|}{ Total Population } & & $\mathrm{Y}$ & & & $X$ & \multirow[b]{2}{*}{$\begin{array}{l}\text { Gini } \\
\text { Coefficient }\end{array}$} & \multirow[b]{2}{*}{$|X-Y|$} & \multirow[b]{2}{*}{$\sigma Y i-1+\sigma Y i(A)$} & \multirow[b]{2}{*}{$\sigma X i-1-\sigma X i(B)$} & \multirow[b]{2}{*}{$A^{*} B$} \\
\hline $\begin{array}{l}\text { Age in } \\
\text { years }\end{array}$ & Population & $\begin{array}{l}\% \\
\text { Population }\end{array}$ & $\begin{array}{l}\text { Cum \% } \\
\text { Populati } \\
\text { on }\end{array}$ & Crashes & $\begin{array}{l}\% \\
\text { Crashes }\end{array}$ & $\begin{array}{l}\text { Cum \% } \\
\text { Crashes }\end{array}$ & & & & & \\
\hline & & 0 & 0 & & 0 & 0 & & & & & \\
\hline 15 to 19 & 733102 & 0.06 & 0.06 & 70 & 0.08 & 0.08 & 0.00 & 0.03 & 0.08 & 0.06 & 0.00 \\
\hline 20 to 29 & 2515051 & 0.19 & 0.25 & 287 & 0.34 & 0.42 & 0.10 & 0.15 & 0.50 & 0.19 & 0.10 \\
\hline 30 to 39 & 2555360 & 0.19 & 0.44 & 188 & 0.22 & 0.64 & 0.21 & 0.03 & 1.06 & 0.19 & 0.21 \\
\hline 40 to 49 & 2553768 & 0.19 & 0.64 & 148 & 0.17 & 0.81 & 0.28 & 0.02 & 1.45 & 0.19 & 0.28 \\
\hline 50 to 59 & 2117968 & 0.16 & 0.80 & 94 & 0.11 & 0.92 & 0.28 & 0.05 & 1.74 & 0.16 & 0.28 \\
\hline 60 to 69 & 1318335 & 0.10 & 0.90 & 43 & 0.05 & 0.98 & 0.19 & 0.05 & 1.90 & 0.10 & 0.19 \\
\hline 70 to 79 & 784596 & 0.06 & 0.96 & 13 & 0.02 & 0.99 & 0.12 & 0.04 & 1.97 & 0.06 & 0.12 \\
\hline $\begin{array}{l}80 \text { and } \\
\text { over }\end{array}$ & 555889 & 0.04 & 1.00 & 8 & 0.01 & 1.00 & & 0.03 & 1.99 & 0.04 & 0.08 \\
\hline Total & 13134067 & 1.00 & & 851 & 1 & & 1.173775317 & & & & 1.26 \\
\hline $\begin{array}{l}\text { Gini's } \\
\text { Coeffic } \\
\text { ient }\end{array}$ & 0.263 & absolute valu & ue(1-1.26) & & & & & & & & \\
\hline
\end{tabular}

